\title{
Resource Allocation Among Cladodes of Opuntia Robusta From East- central Mexico
}

\author{
Héctor Javier León-Solano \\ Universidad Autónoma del Estado de México: Universidad Autonoma del Estado de Mexico \\ Mariusz Krzysztof Janczur ( $\square$ majmx@interia.pl ) \\ Universidad Autónoma del Estado de Mexico https://orcid.org/0000-0002-3886-6710 \\ Emilio González-Camarena \\ Universidad Autónoma del Estado de México: Universidad Autonoma del Estado de Mexico \\ Marcin Czarnoleski \\ Jagiellonian University in Krakow: Uniwersytet Jagiellonski w Krakowie \\ Bartosz Jenner \\ Actelion Pharma Schweiz AG: Actelion Pharmaceuticals Ltd \\ Mario Alberto Sandoval-Molina \\ INECOL: Instituto de Ecologia
}

\section{Original Article}

Keywords: Opuntia robusta, plant secondary metabolites, 4-hydroxybenzoic acid, chlorogenic acid, quercetin, salicylic acid

Posted Date: February 1st, 2021

DOI: https://doi.org/10.21203/rs.3.rs-161086/v1

License: (c) (i) This work is licensed under a Creative Commons Attribution 4.0 International License. Read Full License 


\section{Abstract}

The Optimal Defense Hypothesis $(\mathrm{ODH})$ predicts that younger, more valuable plant organs should be better defended. We tested this hypothesis in Opuntia robusta Wendl. since its sequential, hierarchical and segmented architecture permits the consideration of a possible reallocation of secondary metabolites among cladodes with different age. We performed a field study taking samples of vegetative tissues from cladodes of different orders during eight months, and a field experiment, by covering either apical or basal cladodes with a fabric. We determined the content of 4-hydroxybenzoic acid (4-HBA), chlorogenic acid (CGA), quercetin (QUE) and salicylic acid (SA). 4-HBA and CGA followed the predictions of ODH. QUE followed an inverse tendency. SA did not show any tendency related either with the position of the cladode or the treatment (light vs. shade) however, its concentration was positively correlated with the concentration of 4-HBA. As we detected SA only in a low proportion of cladodes and 4-HBA in all cladodes, we hypothesize the conversion of the latter metabolite to the former one. Contrary to ODH, CGA presented lower concentrations in apical than in basal cladodes when co-occurred with SAL, and QUE was transferred from apical (younger) to basal (older) cladodes. In this study, we found contradictions in the premises and outcomes of both the Resource Availability Hypothesis (RAH) and the $\mathrm{ODH}$, suggesting that a new hypothesis concerning the plant defense against stress factors should be proposed.

\section{Introduction}

Most plants grow under strong herbivory pressure (Coley and Aide 1991; Coley and Barone 1996). To arrest the effect of herbivores, plants produce a wide array of chemical defenses. Different hypotheses have aimed to explain the patterns of defense against herbivores in plants. For example, Optimal Defense Hypothesis (ODH) (McKey 1974) considers that more expensive plant tissues (or, more expensive sexual forms) can be more defended than cheaper ones as a results of optimal energy allocation to defense vs. growth, reproduction and other physiological processes. If so, an optimal pattern of allocation should change with the grazing rate of a given tissue in the absence of defense, with the cost of the allocation of a given defense to that tissue, and with the value of this tissue for the reproductive success of the plant (McKey 1974). For example, if the relative cost of tissue production is low (per tissue biomass unit), then a loss of some amounts of poorly defended but cheap tissue can be easily compensated by tissue regrowth. Also, younger tissues might be expected to be better defended than the older ones, since the former have a higher photosynthetic potential that allows plant to increase the allocation of resources to reproductive tissues, and in turn, to increase the reproductive success, and thus, their loss implies stronger fitness impairment (McKey 1974; Meldau et al. 2012; van Dam et al. 1994). On the other hand, the Resource Availability Hypothesis (RAH) (Coley et al. 1985), forecasts that natural selection favors slow-growing plants with high levels of defense in less productive environments and faster-growing plants with low levels of defense in high-resource environments. Some predictions of both hypotheses, ODH and RAH are not mutually exclusive, because following RAH the biomass of plants growing in less productive environments is more valuable in terms of both energy and fitness, as it is more difficult to recover due to a lower assimilation rate. On the other hand, the two hypotheses lead to contradictory predictions because fast-growing young plants, that generally have more resources available for growth and have a higher photosynthetic potential, should be better defended following ODH but less defended following RAH. Both hypotheses may be applied also to plants' organs assuming that they may grow on either more or less productive plant (a plant is an "environment" for its parts).

Addressing predictions of ODH and RAH, we studied the production of defense substances in Opuntia robusta Wendl. (Cactaceae), an endemic succulent from semiarid highlands of Meridional Plateau, Mexico, which forms three types of populations: strictly hermaphrodite, dioecious (masculine and feminine plants), and trioecious. In this species, hermaphrodite individuals have bisexual flowers, and the other sexual forms, unisexual ones (only the organs of one sexual form are functional) (del Castillo and Argueta 2009). The species chosen by us is a convenient study organism to address ODH and RAH since it grows in a modular way by producing well-defined body units called cladodes, which form easily distinguishable age classes. Importantly, the existence of sequential, hierarchical and segmented architecture of individual plants allows considering a possible reallocation of secondary metabolites among cladodes with different age. Very little is known about secondary metabolites in cladodes of $O$. robusta. Guevara-Figueroa et al. (2010) found 10 different secondary metabolites, including 4hydroxy benzoic (4-HBA) and salicylic acid (SA). Gonzalez-Ponce et al. (2016) found quercetin (QUE) in fruits. As far as we know, only one study confirmed the presence of cyanogenic acid (CGA) in 0 . robusta (Janczur et al. 2020b). There is no study on either the possible defensive function or on ecological aspects of secondary metabolites in this species (but see Janczur et al. (2014) and Janczur et al. (2020b)). Studies of other plant species showed defensive function of some of the metabolites found in Opuntia species, i.e. CGA combated arthropods (Erb et al. 2009; Erb et al. 2014; Kumar et al. 2016; Leiss et al. 2009; Mallikarjuna et al. 2004; Nuessly et al. 2007; Warabieda et al. 2005), microbes (Kliebenstein 2004), or fungi (Mikulic-Petkovsek et al. 2003); 4-HBA combated microbes (Smith-Becker et al. 1998); QUE deterred arthropods (Mallikarjuna et al. 2004), nematodes (Wuyts et al. 2006) and fungi (Padmavati et al. 1997; Parvez et al. 2004). Even if the inductive function of SA that mediates the production of the phenolic compounds is known in several plant species (Caarls et al. 2015; Schweiger et al. 2014; War et al. 2012; War et al. 2011), virtually nothing is known about the possible inductive function of this phytohormone in response to herbivory in Opuntia genus. 
Production of metabolites is energetically costly (Hagerman and Butler 1991; Lincoln 1980; McKey et al. 1978; Skogsmyr and Fagerstrom 1992) and there is evidence to show that resources for secondary metabolite production are often diverted from reproduction (Bergelson and Purrington 1996; Herms and Mattson 1992; Strauss et al. 2002; van Velzen and Etienne 2015). Metabolites used in defense against herbivores take also part in other defensive functions, for example some flavonoids (i.e. QUE) accumulated in plants' epidermal tissue decrease UV transmittance and thus protect against adverse effects of UV light. Plants depend on sunlight for photosynthesis but during this process they are exposed to UV radiation that produces damage in plant's DNA (Schmitz-Hoerner and Weissenbock 2003), damage to photosynthesis apparatus (Correia et al. 2005; Mazza et al. 2000; Musil et al. 2002), negatively affects membranes (An et al. 2000), delays growth, produces leaf discoloration, and reduces vegetative biomass as well as grain yield (Kakani et al. 2003a; Kakani et al. 2003b; Mazza et al. 2000); for review of the effect of UV on plants' growth rate consult Sharma et al. (2017). Several studies showed that both metabolites CGA (Clé et al. 2008; Hectors et al. 2012; Hollosy 2002; Jansen et al. 1998; Jordan 1996) and QUE (Fraser et al. 2017; Lake et al. 2009; Rozema et al. 2002; Wilson et al. 1998) played a role in protecting plants from UV-A and/or UV-B radiation, and thus, exposure to this radiation brings about an increase in their levels. Wilson et al. (1998) observed in leaves of Brassica napus and Solovchenko and SchmitzEiberger (2003) in apple fruits, a UV-B radiation-induced increase of concentration of QUE. B. napus exposed to UV-B radiation exhibited altered morphology and reductions in growth. Additionally, exposure to UV-B radiation for 4 days resulted in a five-fold increase in the QUE : Kaempferol (KAE) ratio: the flavonoid profile shifted from predominantly acylated KAE derivatives to predominantly nonacylated QUE derivatives (Gerhardt et al. 2008). Exposure to UV-B produces response of two systems: the first involves the production of secondary metabolites that absorb UV-B, and the second one is the activation of antioxidant defense systems (Jenkins and Brown 2007; Sharma et al. 2017). Substances absorbing UV are produced and deposited in epidermal cells or hairs (Manetas 2003). QUE absorbs UV radiation with maximum absorbance in the UVA $(\lambda \max =365 \mathrm{~nm})$ and UVC $(\lambda \max =256 \mathrm{~nm})$ and its photoprotective role is probably direct absorption of UV radiation, preventing the formation of reactive oxygen species (ROS) (Russo et al. 2000). The most common antioxidants that act against UV$\mathrm{B}$ radiation are also carotenoids (Sharma et al. 2017).

Higher sunlight intensity, which is one of the indicators of higher environmental productivity, is expected to promote less intense chemical response to herbivory, since at better productivity it is easier to recover lost tissues (Coley et al. 1985), and is expected to promote more intense production of metabolites that protect a plant against UV radiation. So, a plant should solve a dilemma of how to distribute resources among physiological processes, whose effects are frequently opposite. The solution of such disjunctive should produce trade-offs between the proportions of resources allocated in different physiological processes.

In our previous study we found that the tissue of non-parental cladodes of the individuals of Opuntia robusta, contained a higher concentration of total phenolic compound than cladodes that bore sprouts of new cladodes (parental cladodes) (Janczur et al. 2014). Here, we studied whether the differences in the incidence of four secondary metabolites in cladodes of 0 . robusta are a result of their transfer between cladodes from different orders, or cladodes from each order produce these metabolites independently. The direction of a potential flow of secondary metabolites might have important implications for testing plant defense hypotheses. If younger, faster growing cladodes present a higher concentration of secondary metabolites, it would be in accordance with ODH and not with RAH that predicts lower concentration of chemical defenses in faster growing plants. If lower level, light-exposed cladodes, contain either lower or similar concentrations of secondary metabolites than higher-level shaded cladodes, it means that secondary metabolites are transferred from the former to the latter cladodes that is, the plant "takes decision" to send them in that direction, because secondary metabolites are important for the protection of young and thus photosynthetically more valuable tissues. This would be a straightforward argument in support of ODH. If parental shade-exposed cladodes have higher or similar concentrations of secondary metabolites than daughter cladodes, it would mean that the latter photosynthesized the metabolites and sent them to the parental cladodes. The lack of differences may also mean that the secondary metabolites are stable over time, however, in this case, the transfer of a stable secondary metabolite to another compartment containing a secondary metabolite will produce increase of concentration in the latter compartment. If the secondary metabolites are unstable, their concentration or incidence should decrease under shaded conditions: if not, it means that a light-exposed cladode transfers them to the shade-exposed one. If secondary metabolites are produced to deal with UV damage, their concentration should be higher in lighted cladodes, as showed in the studies of Wilson et al. (1998), Solovchenko and Schmitz-Eiberger (2003), Gerhardt et al. (2008), Jenkins and Brown (2007) and (Manetas 2003). However, if a shaded cladode, either parental or daughter to a lighted cladode, contains either a higher or equal concentration of a secondary metabolite, it means that the production of this secondary metabolite is not a response to UV. Ultimately, our study aimed at resolving whether the differences in the probability of incidence or the concentration of secondary metabolites in the cladodes of $O$. robusta result from their reallocation between cladodes of different levels. We explored the following questions: 1 ) Do younger $O$. robustae organs contain a higher concentration (or, higher incidence) of secondary metabolites? 2) Do plants possess a mechanism that allows them the transference of secondary metabolites from older to younger organs?

\section{Methods And Materials}


Study Species. Our field study was conducted on hermaphrodite individuals of Opuntia robusta (Cactaceae). The subgenus of Platyopuntia that this species belongs to, develop photosynthesizing shoots called cladodes, covered by spines that grow on highly specialized branches called areolae (Muñoz-Urias et al. 2008). This plant produces dark-red fruits that contain flavonoids and betalains (Chavez-Santoscoy et al. 2009). Concerning the sex ratio, three kinds of population have been found: strictly hermaphrodite, dioecious (males and females), and trioecious. In the population we are actually working on, we found hermaphrodites, females and very scarce males (approx. 1-2\%), so it can be considered subgynodioecious. The flowering times of different sexual forms overlapped. Even when female flowers were larger when measured in the same day, it was probably an effect of their earlier blossoming. The blossoming begins as early as in late February, spans through June and differs among zones. In the study area, we found the first fruits in April and the last in November (Janczur et al. 2014). More detailed information concerning this species is described elsewhere (del Castillo and Argueta 2009; del Castillo and González-Espinosa 1988; del Castillo and Trujillo-Argueta 2018; Janczur et al. 2014; Sandoval-Molina et al. 2018).

Plant Choice for Field Study. We used the same field-work design as that used in Janczur et al. (2020b). During fieldwork, we chose in each plant branches with the largest number of cladodes. We sampled the vegetative tissues from plants during eight months: on $10 \mathrm{March}$, the second group on 12 April, and so on, through 10 May, 14 June, 12 July, 10 August, 13 September, and 11 October, 2014 (Janczur et al. 2020a).

Plant Choice for Field Experiment. To test whether hermaphrodites of $O$. robusta relocate some secondary metabolites between apical and basal cladodes, and to test whether such relocation is light dependent, we covered some basal and apical cladodes of selected plants, to reduce photosynthetic activity of the covered parts (Fig. 1A and B). The experiment involved plants of similar sizes and plant branches with similar number of cladode orders. To exclude the effects of cladode size and light intensity on the secondary compound production in the vegetative tissues, we found two branches of similar lengths on each plant, with the plain surface of both basal and apical cladodes turned in the same direction with respect to sun. As not all the plants possessed these characteristics on branches with the same cladode orders, the corresponding shaded and lighted cladodes were mostly of 3rd and 4th order, but in few cases, of 2nd and 3rd, or of 4th and 5th orders. We chose only non-lignified cladodes. We randomly assigned the branches for shaded basal and lighted apical cladode and vice versa treatments: that is, both combinations were placed on the same plant. To test the similarity of the cladodes' size and form for both experimental orders, we carried out a slope comparison for the relationship between cladode length and cladode width, between the basal and apical cladodes, using Wald test ( $W_{\mathrm{T}}$ - test statistic); when slopes were similar, we tested the significance of differences between intercepts; we used a numerical algorithm (Warton et al. 2006b) applied in SMATR software (Falster et al. 2003). We did not find significant differences between slopes for this relationship between cladode levels (Likelihood ratio $=1.048, \mathrm{df}=1, \mathrm{P}=0.31$ ).

The Effect of Shading Fabric on Cladode Temperature. To test whether the type of fabric used to shade cladodes had an effect on temperature near cladode surface, we performed an experiment: we measured the temperature on the surface of uncovered cladodes, and on cladodes covered with black cotton coarse fabric or with black cotton coarse fabric lined with white tulle, for twelve hours (8 a.m. through 7 p.m.). We used HOBO data logger model UA-002-64 Pendant Temp/Light. The distributions of the hour-dependent environmental temperatures for non-covered cladodes, and for cladodes covered with cotton coarse fabric or with cotton coarse fabric covered with white tulle were not significantly different from normal distributions at $P \leq 0.05$. The paired t-test showed significant differences between the temperatures of non-covered cladodes and cladodes covered with black cotton coarse fabric $(t=2.88, P=0.015)$, and non-significant differences between the temperatures of non-covered cladodes and cladodes covered with black cotton coarse fabric lined with white tulle $(t$ $=0.84, P=0.42$ ). Given this result, we used the black cotton coarse fabric lined with white tulle for field experiment (Fig. 2; Online Resource S1on Janczur et al. (2020c)).

The Effect of Shading on $\mathrm{pH}$. Following the actually existing knowledge, a more acid average $\mathrm{pH}$ should occur in shaded cladodes due to a higher malic acid concentration in the shortage of light (Bieto and Talón 2008). This is a precursor of carbohydrates in the plant's tissue. That is because in darkness, CAM plants, as is the case of $O$. robusta, maintain their stomata open, while at full light they are closed in order to avoid desiccation. CAM plants absorb $\mathrm{CO}_{2}$ from the air and fix it as oxalic acid at night through PEP carboxilase. A second step in CAM metabolism is the transformation of oxalic acid into malic acid through malate deshidrogenase dependent of NAD ${ }^{+}$. Malic acid formed actively during the night is accumulated with high concentrations in vacuoles that may occupy $95 \%$ of cellular volume. At predawn, acid concentration may be very high (more than $0.2 \mathrm{M}$ ). At full light (stomata closed), malic acid is decarboxilated to pyruvate, forming $\mathrm{CO}_{2}$ inside mesophyll cells that are processed by RUBISCO to form two molecules of 3-PGA (3 Phosphogliceric acid) that is the precursor of carbohydrates. We performed an experiment to examine whether cladode covering by fabrics played a similar role as natural shading. Additionally, to show if $\mathrm{pH}$ is either different or similar in covered as in uncovered cladodes. If it is similar this means that cladodes can transfer the malic acid between them or that their photosynthetic activity is similar. We found in the field 20 plants that bore branches with at least 3 orders of cladodes. The plants were different from those used in both field experiment and field study, but two treatments were the same as those from the experimental design of the field experiment. If they bore more than one three-order branches, we randomly chose only one of them. We assigned a chosen branch from a selected plant to a given experimental group: 1 - Uncovered apical cladode, covered basal cladode, 2 - Covered apical cladodes, uncovered basal cladode, 3 - Uncovered apical and basal cladodes, and 4 - Covered apical and basal

Page $4 / 32$ 
cladodes (Fig. 1; Supplementary Table S2 and S3). On average, branches from each group were located on 6 plants. We covered the cladodes from the experimental groups for three days (January 3 through 5, 2020). During a sunny day, January 5, 2020, we took tissues for $\mathrm{pH}$ estimation using a stainless steel punch $(\varnothing=0.5 \mathrm{~cm})$ to remove approx. $1 \mathrm{~g}$ tissue sample, without going through the cladode's width. We walked from one plant to another taking the samples from the cladode side opposite to the direction of the sun. As the plants were distributed over a large area, it was impossible to take the samples from different plants at the same time, so some combinations of treatment and cladode positions lacked some repetitions in time. However, the combinations of $\mathrm{pH}$ and sampling hour for different experimental groups encompassed the time interval of sample taking in similar way for all groups (Online Resource S2 and S3 on Janczur et al. (2020c)). We macerated each sample of vegetative tissue in a porcelain mortar. After maceration of one sample and before the next maceration, we rinsed the mortar with distillated water. We measured the pH of each sample using the Sper Scientific 850062 LCD Test Tube pH Pen. We put UA002-64 data logger on each cladode, to record the temperature and luminosity during the experiment.

Sampling of the Vegetative Tissue for Secondary Metabolite Determination. In both, field study and field experiment, of each plant, we removed three samples of vegetative tissue from cladodes belonging to each order in field experiment, and to the apical and sub-apical orders, in field experiment, using a stainless steel punch $(\varnothing=0.5 \mathrm{~cm})$. We perforated the mid-section of the arc delimited by the border of the upper quarters of the cladodes, approximately $1 \mathrm{~cm}$ away from the edge (each sample contained the cuticle from both sides of the cladode). Also, we took two samples, approx. $10 \mathrm{~cm}$ away from the midsection. We placed the samples packed in Ziploc bags in a cooler with ice, and transported them to the laboratory in a portable refrigerator at $-20^{\circ} \mathrm{C}$. At the laboratory, they were stored at $-40{ }^{\circ} \mathrm{C}$ until extraction (Janczur et al. 2020b).

Extraction of Secondary Metabolites. We cut $2 \mathrm{~g}$ of each sample from one side of the sample containing the cuticle. We homogenized it with $35 \mathrm{ml}$ of the methanol $100 \%$, and ultrasonicated them in $6 \mathrm{I}$ bath during $30 \mathrm{~min}$ at room temperature. We filtered the methanol extracts obtained, placed them in amber bottles to avoid degradation by light, and stored them at - $20^{\circ} \mathrm{C}$ until processed (Janczur and González Camarena 2018).

Determination of Secondary Metabolites with HPLC. We followed the procedure described elsewhere (Janczur and González Camarena 2018). We used standards for salicylic acid (SA), 4-hydroxybenzoic acid (4-HBA), chlorogenic acid (CGA), and quercetin (QUE), all supplied by SigmaAldrich, and we obtained the following calibration curves: $y_{\mathrm{i}}=1109.4 x_{\mathrm{i}}+481.67, y_{\mathrm{i}}=296.01 x_{\mathrm{i}}+133.74, y_{\mathrm{i}}=551.41 x_{\mathrm{i}}+263.64$, and $y_{\mathrm{i}}=$ 919.96 $x_{\mathrm{i}}+201.64$, where $y_{\mathrm{i}}$ - area below the absorbance curve, $x_{\mathrm{i}}$ - concentration of the secondary metabolite, and $i=1,2,3$ or 4 for 4 -HBA, CGA, QUE, or SA, respectively (Janczur et al. 2020a).

Statistical Analysis. To assess the effect of shading and sampling time on the $\mathrm{pH}$ of the cladodes' vegetative tissue, we used the generalized linear mixed effect model with the identity link function, Gaussian response variable distribution ( $\mathrm{pH})$, and independent variables, treatment (covered, uncovered), cladode position (apical, basal), and nested plant ID, using GLIMMIX procedure of the SAS software. To fit the curves out of the data obtained out of the GLIMMIX procedure, we used the PLM procedure of the SAS software (SAS Institute Inc. 2016; SAS Institute Inc. 2017).

We performed the analyses of the secondary metabolites from the "cladode-point-of-view". To test the effect of the number of cladodes above a given cladode and the cladode order above soil level, on the probability of detection of cladodes bearing a given secondary compound, we performed a logistic regression using generalized linear mixed models (GLMM) with binomial error distribution and "logit" as link function in $\mathrm{R}$ using the glmmTMB package (Brooks et al. 2017). We tested the effect of month of study, the number of cladodes above a given cladode, and the cladode order above soil level, on the probability of detection of cladodes bearing a given secondary metabolite, for female and hermaphrodite cladodes, for the data obtained in a parallel study of us (Janczur et al. 2020a): a combination of levels of a larger number of factors allowed us for a more accurate estimation of the probabilities of occurrence of each secondary metabolite. With the model obtained in this analysis we modeled the probabilities to find a given metabolite in a given cladode, for hermaphrodite individuals. Then, for these probabilities, we fitted a Linear Mixed-Effects Model using the nIme package (Pinheiro et al. 2018), to estimate the differences between months of study, the number of cladodes above a given cladode, and the cladode order above soil level. We treated the month as discrete variables, and the other traits, as continuous variables, since the latter data were ordinal (Sperandei 2014). Models were fitted using in $\mathrm{R}$ (RCoreTeam 2020; RStudioTeam 2020).

For the experiment, we applied an ANOVA model with the variables "conditions" (basal or apical cladode) and treatment (covered or uncovered) and the interaction between them. For 4-HBA and CGA, we compared the concentrations of these metabolites. As the data for QUE and SA contained many zeros, we used the proportion of cladodes bearing these metabolites, instead. We compared the means for the main variables as well as for all the combinations condition $\times$ treatment (SAS Institute Inc. 2017).

We related the concentrations of different secondary metabolites using standardized major axis functions (SMA) (Falster et al. 2003; Warton et al. 2006a). When the number of cladodes containing a given metabolite was very low, we included into analysis only the cladodes

Page 5/32 
containing the substances. We performed the outlier analysis to exclude the atypical concentrations (Barnett and Lewis 1994). To test the similarity of slopes of the relationships between either concentrations of two metabolites or cladode position/treatment, we carried out a slope comparison using Wald test; when slopes were similar, we tested the significance of differences between intercepts applied in SMATR software (Falster et al. 2003; Warton et al. 2006a). These analyses were performed in R (RCoreTeam 2020; RStudioTeam 2020).

\section{Results}

The Effect of Cladode Traits and Sampling Month on the Presence of Secondary Metabolites in Vegetative Tissue. We found a significant effect of May, July, August, and September on the proportion of cladodes with 4-HBA: it was significantly higher in March than in July, August, and September; higher in May than in September; higher in June than in July, August, and September; higher in April than in August and September; higher in October than in July, August, and September (Fig. 3A). May, August, and September had a significant effect on the proportion of cladodes with CGA: it was higher in August than in March, April, June, July, and October; higher in May than in March, June, July; lower in September than in March, April, May, and August; higher in October than in June and September (Fig. 3B). All months had significant effect on the dynamics of the proportion of the cladodes bearing QUE: The proportion of cladodes with QUE was very low in March, increased significantly in April, decreased from May through September, excluding August. Similarly, as in the case of 4-HBA, the proportion of cladodes with QUE increased in October, as compared to all month but April (Fig. 3C; Table 1a; Online Resource S4 on Janczur et al. (2020c)).

The proportions of cladodes bearing 4-HBA and CGA were positively associated with the cladode order from soil and the proportion of cladodes bearing QUE was negatively associated with this trait (Fig. 4 A, B and C; Table 1b). The proportions of 4-HBA and CGA were negatively associated and the proportion of cladodes bearing QUE was positively associated with the number of cladodes above a given cladode (Fig. 4 D, E and F; Table 1c; Online Resource S4 on Janczur et al. (2020c)).

The effect of shading on $\mathrm{pH}$ of the vegetative tissues - The effect of temperature, humidity and sampling hour were correlated, so we adjusted the model for the daytime as the independent variable. The effects of branch type (treatment) and of cladode condition (covered/uncovered) were non significant. Rather daytime had an affect on $\mathrm{pH}$ of the cladodes' vegetative tissue: $\mathrm{pH}$ decreased monotonically until 1 p.m., approximately at 1 p.m. reached its minimum (the highest acidity) and then grew monotonically until approx. 7 p.m. (Fig. 5 A and B; Table 2; Online Resource S2 and S3 on Janczur et al. (2020c)).

The Effect of Cladode Position and of Experimental Light Manipulation on the Presence of Secondary Metabolites in Vegetative Tissue. We detected SA and QUE only in 14 and 12 cladodes out of 96 experimental cladodes, that is, in 15\% and 13\% of cladodes, respectively. These two metabolites did not occur simultaneously (Online Resource S5 on Janczur et al. (2020c)). Because of the low incidence of them, we performed the statistical comparison between both cladode position and treatment using concentrations for 4-HBA and for CGA, and using the proportion of cladodes, for both SA and QUE (Descriptive statistics: Online Resource S6 on Janczur et al. (2020c)).

Contrary to the results of the field study, in the experiment, we found both 4-HBA and CGA in most of the cladodes. The concentrations of 4-HBA or of CGA were not statistically significantly affected by either the position of the cladodes or by the experimental treatment (Fig. 6 and Fig. 7 A through H). However, we observed some effects associated with cladode position and/or treatment. Neither the position nor the treatment alone modified the concentration of 4-HBA (Fig. 6 A and B). Light increased the concentration of this secondary metabolite in apical cladodes with respect to either lighted basal or shaded apical cladodes (Fig. 6 C and D). Lighted apical cladodes had similar 4-HBA concentrations as shaded basal cladodes, higher than shaded apical and lighted basal cladodes that had the same secondary metabolite concentration (Fig. $6 \mathrm{E}$ and F). Shaded basal cladodes had higher 4-HBA concentrations than both lighted basal and shaded apical cladodes (Fig. $6 \mathrm{G}$ and $\mathrm{H}$; Table 3).

There was a tendency towards a higher CGA concentration in both lighted and apical cladodes (Fig. 7 A and B). Light increased CGA concentration in apical cladodes with respect to both lighted basal (Fig. 7 C), shaded apical cladodes (Fig. 7 D), and shaded basal cladodes (Fig. 7 E). Shade did not modify the effect of the cladodes' position (Fig. 7 G and H; Table 3).

The proportion of shaded cladodes did not differ significantly from the proportion of lighted cladodes bearing QUE (Fig. 8 A). Rather the position of a cladode determined the presence of QUE in their tissues: basal cladodes bore QUE with higher probability than apical cladodes (only two cladodes bore this secondary metabolite) (Fig. 8 B). Shading of basal cladodes increased the probability of production of QUE with respect to lighted (Fig. $8 \mathrm{C}$ and E) and to shaded apical cladodes (Fig. $8 \mathrm{E}$ and $\mathrm{H}$ ). Shading did not change the proportion of cladodes bearing QUE either in apical (Fig. 8 D) or in basal cladodes (Fig. $8 \mathrm{G}$ ), and increased this proportion in basal cladodes with respect to shaded apical cladodes (Fig. $8 \mathrm{~F}$ and H; Table 3). 
Contrary to the field study, in the experiment we found SA in a few samples, however the proportion of cladodes bearing it was not associated either to cladode position of treatment (Fig. 9 A through B). Even when the differences between the combinations of cladode positions and experimental treatments were not significant, some tendencies could be observed. For example, light increased the difference in the proportion of cladodes bearing this metabolite between apical and basal cladodes (Fig. $9 \mathrm{C}$ and D), because it increased the proportion of apical cladodes, and decreased the proportion of basal cladodes bearing it. The proportion of cladodes bearing SA was higher for lighted apical than for shaded basal, and higher for shaded apical than for lighted basal (Fig. $9 \mathrm{E}$ and F). It was also higher in shaded basal than in lighted basal cladodes (Fig. 9 H). It was similar in shaded apical and shaded basal cladodes (Fig. 9 H; Table 3; Output of the complete model: Online Resource S7 on Janczur et al. (2020c)).

Relationship between the concentrations of secondary metabolites - Because of the presence of many null concentration values for SA, we analyzed only the SA-positive data, assuming that to test the relationship between two metabolites at least one of them should be present in the tissues. We found positive and significant relationships between the concentrations of 4-HBA and SA for all data, and for lighted cladodes. We removed from the analysis two outliers. This relationship for shaded cladodes was non-significant (Fig. $10 \mathrm{~A}$ ). The difference among slopes of SMAs for lighted and shaded cladodes was on the edge of significance. The relationship between the concentrations of these two metabolites was also positive for both apical, and basal cladodes, however both SMA equations were not significant, even when they explained $36 \%$ and $75 \%$ of the variability, respectively (Fig. 10 B; Table 4; Online Resource S8 on Janczur et al. (2020c)).

We found a positive relationship between the concentration of 4-HBA and CGA for all shaded and lighted apical cladodes. We removed from the model two outliers (Fig. $10 \mathrm{C}$ and D). This relationship was positive for all apical cladodes and negative for basal cladodes (Fig. 10 E). The difference between slopes for apical and basal cladodes was non-significant (Table 4). In basal cladodes, the relationship between the concentrations of these two metabolites was negative and independent of light treatment, even when the dispersal of the data was too large and thus, the relationship was statistically non-significant (Fig. 10 F; Table 4; Online Resource S9 on Janczur et al. (2020c)).

The relationships between the concentrations of SA and CGA were negative for all lighted vs. shaded and for apical vs. basal cladodes (one outlier was removed from the analysis). All relationships were non-significant (Fig. $10 \mathrm{G}$ and $\mathrm{H}$ ). Additionally, in apical cladodes, the concentrations of CGA were very low and the concentration of SA decayed very quickly with a small increase of CGA, or, in other words, the concentration of CGA decreased very slowly with the increase of the SA concentration. The concentrations of CGA for apical cladodes did not overlap with the concentrations of SA for basal cladodes: the slope for the apical cladode differed significantly from the slopes for basal and pooled cladodes (Fig. 10 H; Table 4; Online Resource S10 on Janczur et al. (2020c)).

The relationship between the concentrations of QUE and 4-HBA was negative and non-significant for all lighted and shaded basal cladodes (Fig. 11 A; Table 4; Online Resource S11 on Janczur et al. (2020c)).

The relationship between the concentration of QUE and CGA was positive and non-significant for lighted basal and pooled (lighted and shaded) cladodes. We removed from the analysis two outliers (Fig. $11 \mathrm{~B}$; Table 4). This relationship for shaded basal cladodes was negative and non-significant (Fig. 11 B; Table 4). The slopes for the relationships for shaded cladodes differed significantly from the slopes for the lighted and for the pooled (lighted and shaded) basal cladodes (Table 4; Resource S12 on Janczur et al. (2020c)). We compared here only the basal cladodes for the relationships involving QUE, because only two apical cladodes bore this secondary metabolite (Resource S5 on Janczur et al. (2020c)).

\section{Discussion}

Even when the comparisons of cladodes' conditions and positions for 4-HBA and CGA were statistically not significant, there were some tendencies in the differences between cladode state and position that could be observed. For example, the results suggest that lighted apical cladodes produced 4-HBA and sent it to basal cladodes when they could not produce it by themselves (i.e. when shaded). That is because the incidence of this secondary metabolite was similar in lighted apical cladodes and in shaded basal cladodes, and similar in shaded apical and in lighted basal, but lower than in the former situation.

The relationship between the concentrations of secondary metabolites and cladodes' states that were not obvious in the analysis of separate effect of a given secondary metabolites, were analyzed by us in a regression analysis. The comparison of the relationship between the concentrations of SA and 4-HBA showed that light had an effect on the concentrations of both secondary metabolites and changed the slope of this relationship between shaded and lighted states. Similarly, light changed the relationship for the concentrations of CGA and 4-HBA in apical cladodes. For example, the SMA model predicts that for high concentrations of 4-HBA, the concentrations of both SA and CGA will be higher in shaded than in lighted cladodes. For lower concentrations of 4-HBA these relationships were inverse. Analogously, for high concentrations of SA and for most but the lowest concentrations of CGA, the concentrations of 4-HBA were higher in lighted (vs. SA) or lighted apical (vs. CGA) cladodes. For the relationship CGA vs. 4-HBA most of the concentrations of the latter secondary metabolite were

Page $7 / 32$ 
small, but some less common higher concentrations allowed extending the prediction function for such concentrations. Low concentrations of 4-HBA for the relation SA vs. 4-HBA and moderately low concentrations of this secondary metabolite for the relation CGA vs. 4-HBA were associated with higher concentrations of either SA or CGA in lighted than in shaded cladodes, and vice versa for higher concentrations of 4HBA. Low or moderately low concentrations of 4-HBA were referred to the interval of all the data for this secondary metabolite.

Higher slope of the relationship CGA vs. 4-HBA for lighted than for shaded apical cladodes means that for most concentrations of 4-HBA, lighted cladodes produced higher concentrations of CGA than shaded cladodes. This result, together with a negative non-significant relationship between these two metabolites in basal cladodes and with the observed decrease of CGA concentration in basal cladodes is parallel with the tendency obtained in the comparison of the concentrations of CGA for different cladodes states that suggested an autonomous production of this secondary metabolite by apical cladodes, without a flow from neither lighted nor shaded basal cladodes. The lack of significant differences between cladode states in the comparison of CGA concentration, for example between lighted apical vs. shaded apical cladodes, was probably an effect of the fact that for lower or higher 4-HBA concentration, the relationship between the concentrations of both metabolites was inverse and thus, during the comparisons of the CGA concentrations between different cladodes states, these concentrations were averaged for high and low 4-HGA concentrations.

An analogous phenomenon existed for the relationship between SA and 4-HBA, confirming the observed tendency for higher concentration of SA in lighted apical than in lighted basal, and in lighted apical than in shaded apical cladodes were mainly the outcome of the autonomous production of this secondary metabolite by apical cladodes.

Considering that 1) cladodes are growing more slowly at least during the event of shading and thus, their tissue is more difficult to recover from damage (they are more valuable from both ODH and RAH point of view, and thus, should be better defended); 2) lighted cladodes are more valuable in terms of higher photosynthetic activity (they are more valuable from the ODH point of view and should be better defended) but at the same time are growing faster and thus, their tissue is easier to recover from damage (they are less valuable, from the RAH point of view and should be less defended); and provided that 3) the relationships between pairs of secondary metabolites have different slopes for different cladodes' states, this is difficult to find a congruence between the concepts 1) and 2) and the predictions of either RAH or ODH.

The results of the experiment concerning QUE were concordant with the general tendency of the results of the field study, since basal cladodes from the experiment and cladodes from the field study bearing more daughter cladodes above, that is, the older ones contained this metabolite with higher probability. Both results show that rather the basal position of a cladode determined a higher probability of presence of QUE in its vegetative tissue than the access to light. However, higher and statistically significant probability of detection of QUE in shaded basal cladodes when apical cladodes were lighted, compared to lighted basal cladodes when apical cladodes were shaded and to lighted basal cladodes when apical cladodes were also lighted, suggesting that shaded cladodes received QUE or its precursor from apical cladodes. Since the lighted condition of basal cladodes did not increase the proportion of either shaded or lighted apical cladodes bearing QUE, it probably meant that basal cladodes did not transfer QUE or its precursors to apical cladodes. As the proportion of basal cladodes with QUE was lower under light than in the shade, it meant that 1) QUE was transferred from basal (penultimate order) to the cladodes parental to them, or, 2) QUE was unstable in the light and was decomposed. Similar pH in shaded and lighted cladodes suggests that differences in the probability of detection of QUE were not an effect of higher concentration of the malic acid, precursor of most secondary compounds (Bieto and Talón 2008). This result reinforces the conclusion about the production of QUE in apical cladodes and its transfer to the basal cladodes. Higher incidence of this metabolite in older cladodes obtained in field study, and the existence of significant differences between some combinations of treatment and position were a result of QUE transfer from higher to lower order cladodes that decreased the variability between cladodes and thus, smaller slope of the relationship QUE incidence vs. cladode age. This metabolite was probably not produced to promote cell growth, since higher growth intensity occurs in apical, and thus, younger cladodes: in such case the flow of the secondary metabolite should occur in the opposite direction. Neither was it produced to protect the plant from UV radiation or to rest the effect of free radicals: in both cases, QUE should be moved to both apical and lighted cladodes. These conclusions are parallel with the conclusions of our previous field study in which we did not find in hermaphrodite individuals significant relationships between the incidence of QUE and of meteorological variables that affect both cell growth (air temperature and humidity) and the response against abiotic factors like UV (Janczur and González Camarena 2018). Independently of the proximate causes, the results of both field study and field experiment do not support the predictions of the $\mathrm{ODH}$, since we could not show the existence of significantly higher QUE incidence in younger cladodes even when a mechanism of transport of this secondary metabolite between cladodes existed. They rather support RAH, since slower-growing plant parts in our study had high levels of QUE. This was an analogous result to that predicted by RAH for plants growing in less productive environments (that is, slower-growing). The results showed that the mechanism of the plant is to maintain either similar incidence of this metabolite in cladodes from all levels or to maintain its higher incidence in older cladodes, rather than to transfer them to the youngest cladodes. This is why we proposed in our previous study the use of a relative value of plants' organs (in this case cladodes) in terms of fitness rather than their age (Janczur et al. 2020b). The hierarchical and frequently unilinear architecture of the individuals of 0 . robusta in the population studied here makes the plants sensitive to damage. A loss of lower-order cladodes (closer to soil) brings about a loss of all higher-order cladodes,

Page 8/32 
where reproductive biomass is produced. So, the defense of older cladodes would be justified from an evolutionary standpoint. However, we are aware that in plants with more complex architecture, it is difficult to decide which vegetative organ contributes more in terms of fitness: probably, plant parts that bear reproductive organs. In Opuntia robusta cladodes of any age can potentially produce flowers, however, reproduction is much more probable on apical cladodes.

No study exists concerning the movement of flavonoids between cladodes of any species of Opuntia genus. There is a controversy concerning the possibility of transfer of phenolic compounds from the site of their manufacture to other tissues (Buer et al. 2007; Waller and Nowacki 1978), however it is known that the synthesis of the flavonoid biosynthetic enzyme is light dependent (Jenkins et al. 2001; Kubasek et al. 1998; Pelletier and Shirley 1996). Some researchers state that they are synthesized in the cells in which they accumulate and serve local functions (Peer et al. 2001); however, the results from the study of Buer et al. (2007) showed in Arabidopsis thaliana that flavonoids can move long distances from the light-grown shoot tissues to the shade-grown roots. The authors also suggested the active movement of flavonoids (among them QUE) because of their tissue-specific location, their cell-to-cell movement, and their unidirectional movement when applied midroot. If the movement is diffusion mediated, the flavonoid distribution is less localized and their movement is bidirectional. Our results showed that the movement of QUE was rather unidirectional and light dependent. The stability of QUE is low and its concentration is inversely correlated to temperature and to $\mathrm{pH}$ : its half-life decomposition may last less than one hour at high temperature and high $\mathrm{pH}$, and as long as few hours at low temperature and lower pH (Liu and Zhao 2019; Wang and Zhao 2016). Therefore, it had to either disappear or decrease its concentration (incidence) in the shade, although this did not occur in our study. This reinforces our prediction that in our study, QUE was transferred from lighted apical cladodes to shaded basal cladodes.

In field study, higher order cladodes or the ones that hosted less orders of daughter cladodes contained CGA with higher probability than cladodes basal to them. On the other hand, in the experiment, light increased the difference in the concentration of this metabolite with respect to basal cladodes (both, shaded and lighted), but this effect was statistically not significant. This result showed that apical cladodes produced CGA autonomously, and did not receive it from the basal cladodes. Significant negative relationship between the cladode age (number of daughter cladodes above) and the incidence of CGA obtained in the field study is an effect of the lack of relocation of this secondary metabolite between cladode orders, autonomous production of this compound by higher-order cladodes showed in the experiment, and of low stability of this compound showed in other studies (Gil and Wianowska 2017). Higher CGA concentration in younger (higher-order) cladodes in field study was not an effect of a relocation of this metabolite from lower order to higher order cladodes; that is, plants did not have a "policy" to protect more photosynthetically valuable plant parts, but rather these parts had a "policy" of not sending this metabolite to lower level cladodes. The results of the relationships between the concentrations of CGA and other secondary metabolites confirmed the conclusion from the comparisons between cladodes' states. For example, at states that promote a lower photosynthesis rate (basal, shaded, or shaded basal cladodes), the concentration of CGA either decreased with the increase of, or was non-significantly related with, the other secondary metabolites.

The outcome of this result is concordant with the predictions of ODH although the rhetoric is different: plant cladodes did not defend more valuable cladodes, but rather, these cladodes defended themselves. It was also possible that the plant used CGA to arrest the negative effect of either UV or free radicals, because of a tendency of higher CGA concentration in lighted cladodes, but in such case also basal cladodes should be protected, since a negative effect of this stress factor on basal cladodes would affect apical cladodes, and thus, future reproductive biomass. Also, in field study, higher concentration of CGA in younger cladodes could be an effect of the participation of this metabolite in cell growth (Floh and Handro 2001; Kumar and Pandey 2013; Naoumkina and Dixon 2008; Saslowsky et al. 2005) and/or lignin synthesis (Boerjan et al. 2003; Gamborg 1967). As in our previous study (Janczur et al. 2020b) we did not find a relationship between the incidence of CGA or meteorological factors that might affect growth (temperature, humidity) and increase the negative effect of UV (radiation intensity), we suggest that in this population of 0 . robusta, this metabolite plays a defensive role. In any case, the response to non-biotic stress factors should be similar to the response to biotic factors, that is, "respond when you are attacked". Our study showed that, contrary to the predictions of $\mathrm{ODH}$, when CGA coexisted with SA, older tissues contained higher concentrations of this metabolite. We are not sure why it occurred, however this result was contradictory to both the results of field study and the non-significant tendency in the experiment, although as the coexistence of SA and CGA was non-frequent, these data did note affect the general pattern. Independently of a low dataset for the relationship between the concentrations of SA and CGA, we can conclude that SA was not an elicitor of the CGA. Larger dataset would show if the coexistence of these two secondary metabolites is associated to a lack of relationship between them or may otherwise suggest that they are competing for the same precursor. High percentage of model explanation for basal cladodes suggests that a small increase of the sample will bring about a significant relationship between the concentrations of these two substances.

The positive cladode-position-independent relationship between the concentrations of 4-HBA and SA in field experiment was probably an effect of the conversion of the former into the latter. If it had been a case of a promoting action of the SA, this metabolite would have been more common and 4-HBA an either less or equally common metabolite. We are not sure why we did not find SA in the field study and found it during experiment. If it had been an elicitor for the production of other substances in response to the stress factor (fabric bag covering

Page $9 / 32$ 
cladodes) as mentioned in several studies (Beckers and Spoel 2006; Mendoza et al. 2018; Sudha and Ravishankar 2003), it would have had a positive relationship with other secondary metabolites. However, it had negative non-significant relationship with some secondary metabolites as determined in this study. The model of positive relationship between the concentrations of SA and 4-HBA explained a considerable proportion of variance although the number of data points was low. Additionally, three out of five regression lines were significant. The nonsignificant relationships also explained a considerable proportion of variance (36\%, $39 \%$, and $75 \%)$ suggesting that additional data had brought about a statistical significance.

It is not clear why 4-HBA was converted into SA in only few samples (if it was a case), since the pathway involving 4-HBA as a precursor of the latter compound is very common (Lee et al. 1995). Another pathway is also possible, i.e. phenylalanine $\diamond$ trans-cinnamic acid $\diamond$ benzoic acid $\diamond \mathrm{SA}$, together with a parallel pathway phenylalanine $\diamond$ trans-cinnamic acid $\diamond 4$-coumaric acid $\diamond 4$-HBA. Following this pathway, the synthesis of 4-HBA may compete for precursor (trans-cinnamic acid) with SA. As SA is known mainly for its signaling properties in the induction of pathogenesis-related proteins (Bennett and Wallsgrove 1994; Pierpoint 1994; Pieterse et al. 2012) and cases of signaling function of 4-HBA are scarcely known (Schnitzler et al. 1992; Tan et al. 2004; Ulmasov et al. 1994), it is possible to put forward the following hypotheses: 1) 4-HBA was produced in 0 . robusta for defensive purposes; SA was produced only in few cladodes either because the response against herbivores was not SA-signaling-dependent or there were no other stress factors requiring SA signaling; 2 ) The production of 4-HBA was higher in priority than that of SA synthesis, thus, sharing the same precursor, the plant lacked sufficient resources to produce both of them. If the conversion of 4-HBA to SA in the cladodes were a phenomenon, it would mean that the latter secondary metabolite was not produced in response to UV, since in either the lighted or the apical cladodes, the concentration of SA increased slower than in either the shaded or the basal cladodes. This effect should be confirmed in larger sample: because of a low incidence of this secondary metabolite, only a few cladodes had high concentration of 4-HBA.

In the present study 4-HBA and QUE showed dynamics in hermaphrodite cladodes during eight-months study period. Both metabolites showed a nearly monotonic dynamics: the incidence of the 4-HBA decreased from March through September with the exception of October, and the incidence of QUE increased from March through October, with the exceptions of April and September. This result is parallel with the result of the field experiment that showed a negative non-significant relationship between these two metabolites. This dynamic occurred probably because QUE was either relocated among cladodes from different ages or cladodes stopped producing them. This reallocation may have produced the following effect: if both mutually dependent cladodes contained a given metabolite, a complete relocation from an apical to a basal cladode would bring about a lower proportion of apical cladodes bearing that given secondary metabolite. It would produce the same effect as an incomplete relocation from apical to basal cladode, together with the lack of production of new secondary metabolite and/or, decomposition of the remainder metabolite. The transfer of QUE from apical to basal cladodes shown in field experiment was concordant with this result. Higher QUE incidence in older cladodes shown in field study points out that during the season the incidence of this metabolite increased because the proportion of older cladodes bearing it also increased. As the tendency of 4-HBA to move in the same direction was slight in the field experiment, this dynamics was probably produced by the higher mobility of QUE and the dynamics of the incidence of 4-HBA followed inversely this tendency because of the reasons already described (i.e. competition for the same precursor). Independently of the proximate causes, this result is not concordant with ODH because the proportion of cladodes bearing QUE was lower when tissues were younger and it increased throughout season when tissue was older. At the same time, it was concordant with RAH, because the prevalence of QUE was higher when tissues' growth rate was lower because they were older. The contradiction was inverse for 4HBA with respect to ODH and RAH. The probability of detection of CGA in cladodes of $O$. robusta did not follow the predictions of any of the hypotheses mentioned, because it did not follow monotonic seasonal dynamics. Its dynamics were mainly a result of an atypically high prevalence in August and low prevalence in September: its incidence in other months did not follow a clear tendency. This result suggests either 1) a lower mobility and/or, 2) a higher stability of this metabolite in the tissues of O. robusta. As the study of Gil and Wianowska (2017) evidenced a low stability of this metabolite, and our experiment showed that CGA is not transferred from apical to basal cladodes, the atypical CGA incidences occurred because of a higher insulation in August and lower insulation or decomposition of this compound in September.

Even when several studies showed the involvement of SA in resistance and tolerance to many abiotic factors (i.e. ozone, UV radiation, heat, cold (Dempsey and Klessig 2017; Horváth et al. 2007; Rivas-San Vicente and Plasencia 2011; Yuan and Lin 2008)) in our study the incidence of SA was similar at light than in the shade. It meant that the production of this secondary metabolite was not a response against short-term action of UV. However, this metabolite could probably take part in tissue growth, since the proportion of apical cladodes was statistically nonsignificantly higher in apical cladodes. It is difficult to conclude whether the lack of significant differences in SA incidence between cladode positions and experimental treatments was a result of the lack or of only a low-intensity transport of this secondary metabolite between cladodes from different levels, since this process has not been studied in Cactaceae. There is no unique transport mechanism in different plant species (Maruri-López et al. 2019). The process of transport of this metabolite throughout vegetative tissues is known only scarcely (Maruri-López et al. 2019). However, several studies showed that SA has a weak solubility in acids and in water, and crosses through cell plasma membranes by pH-dependent diffusion and carrier-mediated mechanisms (Bonnemain et al. 2013; Chen et al. 2001; Maruri-López et 
al. 2019; Takanaga et al. 1994). In our study, there was no significant difference in pH between either the apical and basal or covered and uncovered cladodes. This lack of differences in $\mathrm{pH}$ was probably responsible for the lack of significant differences in the incidence of this SA in apical/basal and shaded/lighted cladodes. In other words, there existed only a reduced transfer of SA between cladodes, because of the lack of difference in $\mathrm{pH}$ between cladodes. As SA is known for its elicitor action for other secondary metabolites, the absence of biotic stress was probably responsible for the small proportion of cladodes bearing it. As experimental treatments were a kind of stress, the presence of tulle bags exerted a stressful effect on cladodes, similar to that exerted by non-biotic factors. No one out of the three other secondary metabolites studied here responded to the presence of SA in a manner that could be perceived as elicitation. Even more, the concentrations of CGA and SA were associated inversely, probably due to the competition for the same precursor, i.e. phenylalanine (Chen et al. 2009; Dempsey et al. 2011; Tuan et al. 2014).

The negative (non-significant) relationship between the concentrations of QUE and 4-HBA may be explained in two ways: 1) They shared of a common precursor for the synthesis of both secondary metabolites (Bennett and Wallsgrove 1994) that is, enhanced synthesis of 4-HBA brought about a decrease of the concentration of QUE (or, vice versa), or 2) The negative relationship is a result of the fact that high concentrations of QUE corresponded to basal (mainly, shaded basal) cladodes, and that high concentrations of 4-HBA corresponded to lighted apical and to shaded basal cladodes. Analogously, the negative (non-significant) relationships between the concentrations of QUE and CGA for shaded basal cladodes may be explained by 1), or by the fact that for shaded basal cladodes, high concentrations of QUE cooccurred with low concentrations of CGA. On the other hand, in lighted basal cladodes low and high concentrations of both QUE and CGA cooccurred. As these relationships were non-significant, it is difficult to discuss the representativeness of this result at population level. However, it showed that both secondary metabolites responded to the presence of light in independent manner and were an effect of very short exposure to experimental treatments. To the best of our knowledge, CGA is not an elicitor of the secondary metabolites studied here, since only one case of an elicitor activity of QUE is actually known (Mahady and Beecher 1994), so a possible positive relationship between the concentrations of QUE and CGA in lighted cladodes was rather an effect of an independent production of secondary metabolites as a response against different stress factors.

QUE and SA did not co-occur. This means that SA did not promote the production of QUE. Neither did it promote the production of CGA, since the relationship between theses two metabolites was negative and statistically not significant. It rather means that these two secondary metabolites competed for the same precursors.

Regardless of the proximate factors that explain the relationships between the concentrations of different secondary metabolites studied here (i.e. elicitor effect, or competition for the same precursor) either the incidence or the concentration of different secondary metabolites maintain a rather complex, frequently negative, relationship with the analogue variables of other secondary metabolites, and thus, this is difficult to expect a congruent pattern of their presence in younger or faster-growing plants' vegetative tissues. Additionally, there does not exist a general pattern of the between-cladode dynamics for different secondary metabolites. Rather, each of them is produced for a particular purpose and its incidence or dynamics depend on the goal it was synthetized for, and of either the competition for the same precursor or a possible elicitor function. Probably, the whole response (all chemical and physical defenses) of a plant against the action of herbivores should be studied to propose a new hypothesis concerning plant defense. However, this is difficult to achieve, since a matrix of metabolites and of the herbivores against which these metabolites were produced should be studied in such case. A reductionist approach may be used, when a specific secondary metabolite is used for a specific herbivore. Neither does there exist a unified hypothesis concerning plant's response to the joint action of herbivores and abiotic stress such as UV. If a secondary metabolite protects a plant against both factors, its concentration should increase in the organs where the stress factor is exerting the main damage. However, if different substances sharing the same precursor are used for two different kinds of defenses (i.e. herbivory and UV), the investment to herbivory may take away resources from the defense against the negative effect of UV or vice versa. In such case, the resources will be allocated to the process that affects more severely the reproductive success.

Since in the experiment the cotton coarse fabric did not change significantly cladodes' temperature, and the $\mathrm{pH}$ among the covered and uncovered cladodes did not differ, it meant that covered cladodes did not open their stomata, because the temperature of cladodes' surface was similarly high during daytime as exposed to the environmental temperature. So, the concentrations of the malic acid were similar in both experimental treatments and in both cladodes' positions. Therefore, we consider that any difference or the lack of differences in secondary metabolite concentration between treatments was an effect of either metabolite transfer between cladodes and not of a different concentration of the precursor (malic acid).

\section{Conclusions}

The ODH predicts that younger, more valuable plant organs should be better defended. In this study, 4-HBA and CGA followed the predictions of this hypothesis. QUE followed an inverse tendency. We did not find SA in the field study even when we found it in the field experiment. SA 
did not show any tendency related either with the position of the cladode (apical vs. basal) or the treatment (light vs. shade) however, its concentration was positively correlated with the concentration of 4-HBA. As we detect SA only in a low proportion of cladodes and 4-HBA in all cladodes, we hypothesize the conversion of the latter metabolite to the former one. For the same reason, SA probably did not serve as elicitor. Also, contrary to the prediction of ODH, CGA presented lower concentrations in apical than in basal cladodes when co-occurred with SA. The incidence of QUE did not hold the predictions of the $\mathrm{ODH}$, since in the field experiment this secondary metabolite was transferred from apical to basal cladodes. This transfer was probably responsible for the existence of a tendency for a higher incidence of QUE in older than in younger cladodes obtained in the field study. A lower incidence of CGA in older cladodes was an effect of an autonomous lightdependent production of this secondary metabolite in apical cladodes and its quick decomposition in basal cladodes. Also, the results of field experiment suggested an autonomous synthesis of SA in apical cladodes, without relocation from basal to apical cladodes. High mobility of QUE between cladodes, a tendency of 4-HBA to be transferred between cladodes, and an autonomous way of CGA production in apical cladodes showed in field experiment together with its quick decomposition rate shown in other studies that occurred in basal cladodes, explained why in the field study carried out in another study of ours (Janczur et al. 2020b), 4-HBA and QUE presented a statistically significant, almost monotonic dynamic over eight-months, contrary to CGA.

In the present study, we found contradictions in the premises and outcomes of both the RAH and the ODH and suggests that a new hypothesis concerning the plant defense against stress factors should be proposed.

\section{Declarations}

Acknowledgements We extend our appreciation to the Municipio de Singuilucan for granting us permission to conduct the study in its jurisdiction and the Pérez Juarez as well as Samperio Pérez families for allowing us to work in their lands at San Nicolas Tecoaco. Sergio Quesada edited the English text. Lupita Tzenyatze Solache Ramos and Michele García Conejo helped us during fieldwork.

Authors' contributions Conceptualization: MCZ, HJLS, MKJ; Data curation: BJ, MASM, MKJ; Funding acquisition: MKJ; Investigation: HJLS, EGC, MASM, MKJ, MCZ; Field work: HJLS, EGC, MKJ; Laboratory work: EGC, HJLS; Project administration: MKJ; Writing-original draft preparation: MKJ, MASM; Writing-review and editing: MKJ, HJLS, MASM, MCZ. All authors read and approved the final manuscript.

Funding This work was supported by the Consejo Nacional de Ciencia y Tecnología, grant 180694 to MKJ

Competing interests The authors have no conflicts of interest to declare that are relevant to the content of this article

Compliance with ethical standards The research did not involve measurements on humans or animals. We obtained the permission of the Secretaria de Medio Ambiente y de Recursos Naturales (SEMARNAT) to carry out research on wild plants, and of the head of the Municipality of Singuilucan, State of Hidalgo, Mexico (Secretario General Municipal de Singuilucan, Estado de Hidalgo, México) to carry out research activities on the lands administered by the Municipality. The study site is not considered a protected area (SEMARNAT 2013), and O. robusta is not considered an endangered species (SEMARNAT 2010). To the best of our knowledge, we did not affect or involve any endangered species during the study. No plant was killed or severely damaged as a result of our research activity; the plant material used for this study was sampled only at a very limited scale, and sampling therefore had negligible effects on broader ecosystem functioning

\section{References}

1. An L, Feng H, Tang X, Wang X (2000) Changes of microsomal membrane properties in spring wheat leaves (Triticum aestivum L.) exposed to enhanced ultraviolet-B radiation. J Photochem Photobiol B 57:60-65. https://doi.org/10.1016/S1011-1344(00)00077-4

2. Barnett V, Lewis T (1994) Outliers in statistical data (3 ed.). Wiley Series in Probability and Statistics. Wiley, USA

3. Beckers GJM, Spoel SH (2006) Fine-tuning plant defence signalling: salicylate versus jasmonate. Plant Biol 8:1-10. https://doi.org/10.1055/s-2005-872705

4. Bennett RN, Wallsgrove RM (1994) Secondary metabolites in plant defence mechanisms. New Phytol 127:617-633. https://doi.org/10.1111/j.1469-8137.1994.tb02968.x

5. Bergelson J, Purrington CB (1996) Surveying patterns in the cost of resistance in plants. Am Nat 148:536-558. https://doi.org/10.1086/285938

6. Bieto JA, Talón M (2008) Fundamentos de fisiología vegetal. McGraw-Hill Interamericana, España

7. Boerjan W, Ralph J, Baucher M (2003) Lignin biosynthesis. Annu Rev Plant Biol 54:519-546. https://doi.org/10.1146/annurev.arplant.54.031902.134938

8. Bonnemain J-L, Chollet J-F, Rocher F (2013) Transport of salicylic acid and related compounds. In: Hayat S, Ahmad A, Alyemini MN (eds) Salicylic Acid. Plant Growth and Development. Springer, Dordrecht, pp 43-59. https://doi.org/10.1007/978-94-007-6428-6_4

Page 12/32 
9. Brooks M, Kristensen K, van Benthem K, Magnusson A, Berg CW, Nielsen A, Skaug H, Mächler M, Bolker B (2017) glmmTMB balances speed and flexibility among packages for zero-inflated generalized linear mixed modeling. R Journal 9:378-400. https://doi.org/10.32614/RJ-2017-066

10. Buer CS, Muday GK, Djordjevic MA (2007) Flavonoids are differentially taken up and transported long distances in Arabidopsis. Plant Physiol 145:478-490. https://doi.org/10.1104/pp.107.101824

11. Caarls L, Pieterse CMJ, Van Wees SCM (2015) How salicylic acid takes transcriptional control over jasmonic acid signaling. Front Plant Sci 6:170. https://doi.org/10.3389/fpls.2015.00170

12. Chavez-Santoscoy RA, Gutierrez-Uribe JA, Serna-Saldivar SO (2009) Phenolic composition, antioxidant capacity and in vitro cancer cell cytotoxicity of nine prickly pear (Opuntia spp.) juices. Plant Foods Hum Nutr 64:146-152. https://doi.org/10.1007/s11130-009-0117-0

13. Chen HJ, Hou WC, Kuć J, Lin YH (2001) Ca2+-dependent and Ca2+-independent excretion modes of salicylic acid in tobacco cell suspension culture. J Exp Bot 52:1219-1226. https://doi.org/10.1093/jexbot/52.359.1219

14. Chen Z, Zheng Z, Huang J, Lai Z, Fan B (2009) Biosynthesis of salicylic acid in plants. Plant Signal Behav 4:493-496. https://doi.org/10.4161/psb.4.6.8392

15. Clé C, Hill LM, Niggeweg R, Martin CR, Guisez Y, Prinsen E, Jansen MA (2008) Modulation of chlorogenic acid biosynthesis in Solanum lycopersicum; consequences for phenolic accumulation and UV-tolerance. Phytochemistry 69:2149-2156. https://doi.org/10.1016/j.phytochem.2008.04.024

16. Coley PD, Aide TM (1991) Comparison of herbivory and plant defenses in temperate and tropical broad-leaved forests. In: Price PW, Lewinsohn TM, Fernandes GW, Benson WW (eds) Plant-animal interactions: evolutionary ecology in tropical and temperate regions. Willey \& Sons, NY, pp 25-49

17. Coley PD, Barone JA (1996) Herbivory and plant defenses in tropical forests. Annu Rev Ecol Syst 27:305-335. https://doi.org/10.1146/annurev.ecolsys.27.1.305

18. Coley PD, Bryant JP, Chapin FS, 3rd (1985) Resource availability and plant antiherbivore defense. Science 230:895-899. https://doi.org/10.1126/science.230.4728.895

19. Correia CM, Pereira JMM, Coutinho JF, Björn LO, Torres-Pereira JMG (2005) Ultraviolet-B radiation and nitrogen affect the photosynthesis of maize: a Mediterranean field study. Eur J Agron 22:337-347. https://doi.org/https://doi.org/10.1016/j.eja.2004.05.002

20. del Castillo RF, Argueta ST (2009) Reproductive implications of combined and separate sexes in a trioecious population of Opuntia robusta (Cactaceae). Am J Bot 96:1148-1158. https://doi.org/10.3732/ajb.0800301

21. del Castillo RF, González-Espinosa M (1988) Una interpretación evolutiva del polimorfismo sexual de Opuntia robusta (Cactaceae). Agrociencia 71:185-196

22. del Castillo RF, Trujillo-Argueta S (2018) On the possible role of nonreproductive traits for the evolution of unisexuality: Life-history variation among males, females, and hermaphrodites in Opuntia robusta (Cactaceae). Ecol Evol 8:6988-7001. https://doi.org/10.1002/ece3.4217

23. Dempsey DA, Klessig DF (2017) How does the multifaceted plant hormone salicylic acid combat disease in plants and are similar mechanisms utilized in humans? BMC Biol 15:23. https://doi.org/10.1186/s12915-017-0364-8

24. Dempsey DA, Vlot AC, Wildermuth MC, Klessig DF (2011) Salicylic acid biosynthesis and metabolism. Arabidopsis Book 9:e0156. https://doi.org/10.1199/tab.0156

25. Erb M, Flors V, Karlen D, De Lange E, Planchamp C, D’Alessandro M, Turlings TCJ, Ton J (2009) Signal signature of aboveground-induced resistance upon belowground herbivory in maize. Plant J 59:292-302. https://doi.org/10.1111/j.1365-313X.2009.03868.X

26. Erb M, Gordon-Weeks R, Flors V, Camañes G, Turlings TCJ, Ton J (2014) Belowground ABA boosts aboveground production of DIMBOA and primes induction of chlorogenic acid in maize. Plant Signal Behav 4:639-641. https://doi.org/10.4161/psb.4.7.8973

27. Falster DS, Warton DI, Wright IJ (2003) (S)MATR: standardised major axis tests and routines. Version 2.0.

28. Floh EIS, Handro W (2001) Effect of photoperiod and chlorogenic acid on morphogenesis in leaf discs of Streptocarpus nobilis. Biol Plantarum 44:615-618. https://doi.org/10.1023/a:1013771510289

29. Fraser DP, Sharma A, Fletcher T, Budge S, Moncrieff C, Dodd AN, Franklin KA (2017) UV-B antagonises shade avoidance and increases levels of the flavonoid quercetin in coriander (Coriandrum sativum). Sci Rep 7:17758. https://doi.org/10.1038/s41598-017-18073-8

30. Gamborg OL (1967) Aromatic metabolism in plants. V. The biosynthesis of chlorogenic acid and lignin in potato cell cultures. Can J Biochem 45:1451-1457

31. Gerhardt KE, Lampi MA, Greenberg BM (2008) The effects of far-red light on plant growth and flavonoid accumulation in Brassica napus in the presence of ultraviolet B radiation. Photochem Photobiol 84:1445-1454. https://doi.org/10.1111/j.1751-1097.2008.00362.x 
32. Gil M, Wianowska D (2017) Chlorogenic acids - their properties, occurrence and analysis. Annales Universitatis Mariae Curie-Skłodowska Lublin - Polonia, Sectio AA 72:61-104. https://doi.org/10.17951/aa.2017.72.1.61

33. Gonzalez-Ponce HA, Martinez-Saldana MC, Rincon-Sanchez AR, Sumaya-Martinez MT, Buist-Homan M, Faber KN, Moshage H, JaramilloJuarez F (2016) Hepatoprotective effect of Opuntia robusta and Opuntia streptacantha fruits against acetaminophen-induced acute liver damage. Nutrients 8:607. https://doi.org/10.3390/nu8100607

34. Guevara-Figueroa T, Jimenez-Islas H, Reyes-Escogido ML, Mortensen AG, Laursen BB, Lin LW, De Leon-Rodriguez A, Fomsgaard IS, de la Rosa APB (2010) Proximate composition, phenolic acids, and flavonoids characterization of commercial and wild nopal (Opuntia spp.). J Food Comp Anal 23:525-532. https://doi.org/10.1016/j.jfca.2009.12.003

35. Hagerman AE, Butler LG (1991) Chapter 10 - Tannins and Lignins. In: Rosenthal GA, Berenbaum MR (eds) Herbivores: their interactions with secondary plant metabolites (second edition). Academic Press, San Diego, pp 355-388. https://doi.org/10.1016/B978-0-12-597183$6.50015-2$

36. Hectors K, van Oevelen S, Guisez Y, Prinsen E, Jansen MA (2012) The phytohormone auxin is a component of the regulatory system that controls UV-mediated accumulation of flavonoids and UV-induced morphogenesis. Physiol Plant 145:594-603. https://doi.org/10.1111/j.1399-3054.2012.01590.x

37. Herms DA, Mattson WJ (1992) The dilemma of plants: to grow or defend. Q Rev Biol 67:283-335. https://doi.org/10.1086/417659

38. Hollosy F (2002) Effects of ultraviolet radiation on plant cells. Micron 33:179-197. https://doi.org/10.1016/S0968-4328(01)00011-7

39. Horváth E, Szalai G, Janda T (2007) Induction of abiotic stress tolerance by salicylic acid signaling. J Plant Growth Regul 26:290-300. https://doi.org/10.1007/s00344-007-9017-4

40. Janczur MK, González Camarena E (2018) Binary HPLC method for determination of 4-hydroxybenzoic acid (4-HBA), chlorogenic acid (CGA), quercetin (QUE), and salicilic acid (SAL). Protocols.io. https://doi.org/10.17504/protocols.io.mhac32e

41. Janczur MK, González-Camarena E, Jenner B (2020a) Replication data for: Implications of the existence of separated sexual forms of Opuntia robusta for plant defense hypotheses, V1 edn. Harvard Dataverse. https://doi.org/10.7910/DVN/LERCFK

42. Janczur MK, González-Camarena E, León-Solano HJ, Sandoval-Molina MA, Jenner B (2020b) Implications of the existence of separated sexual forms of Opuntia robusta for plant defense hypotheses. Submitted

43. Janczur MK, León Solano HJ, González Camarena E, Czarnoleski M, Jenner B, Sandoval-Molina MA (2020c) Replication Data for: Resource allocation among cladodes of Opuntia robusta from the Central-Eastern Mexico, V1 edn. Harvard Dataverse. https://doi.org/10.7910/DVN/IQZKDD

44. Janczur MK, León Solano HJ, Solache Rámos LT, Mendoza Reyes CH, Oro Cerro MdC, Mariezcurrena Berasain MD, Rivas Manzano IV, Manjarrez J, Villareal Benitez JL, Czarnoleski M (2014) Chemical and physical defense traits in two sexual forms of Opuntia robusta in Central Eastern Mexico. PLoS ONE 9:e89535. https://doi.org/10.1371/journal.pone.0089535

45. Jansen MAK, Gaba V, Greenberg BM (1998) Higher plants and UV-B radiation: balancing damage, repair and acclimation. Trends Plant Sci 3:131-135. https://doi.org/10.1016/S1360-1385(98)01215-1

46. Jenkins GI, Brown BA (2007) UV-B Perception and Signal Transduction. In: Whitelam GC, Halliday KJ (eds) Annual Plant Reviews Volume 30: Light and Plant Development. pp 155-182. https://doi.org/10.1002/9780470988893.ch7

47. Jenkins GI, Long JC, Wade HK, Shenton MR, Bibikova TN (2001) UV and blue light signalling: pathways regulating chalcone synthase gene expression in Arabidopsis. New Phytol 151:121-131. https://doi.org/10.1046/j.1469-8137.2001.00151.x

48. Jordan BR (1996) The effects of ultraviolet-B radiation on plants: a molecular perspective. Adv Bot Res 22:97-162. https://doi.org/10.1016/S0065-2296(08)60057-9

49. Kakani VG, Reddy KR, Zhao D, Mohammed AR (2003a) Effects of ultraviolet-B radiation on cotton (Gossypium hirsutum L.) morphology and anatomy. Ann Bot 91:817-826. https://doi.org/10.1093/aob/mcg086

50. Kakani VG, Reddy KR, Zhao D, Sailaja K (2003b) Field crop responses to ultraviolet-B radiation: a review. Agric For Meteorol 120:191-218. https://doi.org/https://doi.org/10.1016/j.agrformet.2003.08.015

51. Kliebenstein DJ (2004) Secondary metabolites and plant/environment interactions: a view through Arabidopsis thaliana tinged glasses. Plant, Cell Environ 27:675-684. https://doi.org/10.1111/j.1365-3040.2004.01180.x

52. Kubasek WL, Ausubel FM, Shirley BW (1998) A light-independent developmental mechanism potentiates flavonoid gene expression in Arabidopsis seedlings. Plant Mol Biol 37:217-223. https://doi.org/10.1023/a:1005977103116

53. Kumar P, Ortiz EV, Garrido E, Poveda K, Jander G (2016) Potato tuber herbivory increases resistance to aboveground lepidopteran herbivores. Oecologia 182:177-187. https://doi.org/10.1007/s00442-016-3633-2

54. Kumar S, Pandey AK (2013) Chemistry and biological activities of flavonoids: an overview. Sci World J 2013:162750. https://doi.org/10.1155/2013/162750

Page 14/32 
55. Lake JA, Field KJ, Davey MP, Beerling DJ, Lomax BH (2009) Metabolomic and physiological responses reveal multi-phasic acclimation of Arabidopsis thaliana to chronic UV radiation. Plant Cell Environ 32:1377-1389. https://doi.org/10.1111/j.1365-3040.2009.02005.x

56. Lee HI, Leon J, Raskin I (1995) Biosynthesis and metabolism of salicylic acid. Proc Natl Acad Sci USA 92:4076-4079. https://doi.org/10.1073/pnas.92.10.4076

57. Leiss KA, Maltese F, Choi YH, Verpoorte R, Klinkhamer PGL (2009) Identification of chlorogenic acid as a resistance factor for thrips in Chrysanthemum. Plant Physiol 150:1567-1575. https://doi.org/10.1104/pp.109.138131

58. Lincoln DE (1980) Leaf resin flavonoids of Diplacus aurantiacus. Biochem Syst Ecol 8:397-400. https://doi.org/10.1016/03051978(80)90043-5

59. Liu W-N, Zhao X-H (2019) Changes of the stability and bioactivity of quercetin and myricetin in BGC-823 cells in response to heat treatment and Fe2+/Cu2+ addition. J Food Meas Charact 13:3285-3297. https://doi.org/10.1007/s11694-019-00250-0

60. Mahady GB, Beecher CW (1994) Quercetin-induced benzophenanthridine alkaloid production in suspension cell cultures of Sanguinaria canadensis. Planta Med 60:553-557. https://doi.org/10.1055/s-2006-959570

61. Mallikarjuna N, Kranthi KR, Jadhav DR, Kranthi S, Chandra S (2004) Influence of foliar chemical compounds on the development of Spodoptera litura (Fab.) in interspecific derivatives of groundnut. J Appl Entomol 128:321-328. https://doi.org/10.1111/j.14390418.2004.00834.x

62. Manetas $Y$ (2003) The importance of being hairy: the adverse effects of hair removal on stem photosynthesis of Verbascum speciosum are due to solar UV-B radiation. New Phytol 158:503-508. https://doi.org/10.1046/j.1469-8137.2003.00768.x

63. Maruri-López I, Aviles-Baltazar NY, Buchala A, Serrano M (2019) Intra and extracellular journey of the phytohormone salicylic acid. Front Plant Sci 10:423. https://doi.org/10.3389/fpls.2019.00423

64. Mazza CA, Boccalandro HE, Giordano CV, Battista D, Scopel AL, Ballare CL (2000) Functional significance and induction by solar radiation of ultraviolet-absorbing sunscreens in field-grown soybean crops. Plant Physiol 122:117-125.

https://doi.org/10.1104/pp.122.1.117

65. McKey D (1974) Adaptive patterns in alkaloid physiology. Am Nat 108:305-320. https://doi.org/10.2307/2459893

66. McKey D, Waterman PG, Mbi CN, Gartlan JS, Struhsaker TT (1978) Phenolic content of vegetation in two African rain forests: ecological implications. Science 202:61-64. https://doi.org/10.1126/science.202.4363.61

67. Meldau S, Erb M, Baldwin IT (2012) Defence on demand: mechanisms behind optimal defence patterns. Ann Bot 110:1503-1514. https://doi.org/10.1093/aob/mcs212

68. Mendoza D, Cuaspud O, Arias JP, Ruiz O, Arias M (2018) Effect of salicylic acid and methyl jasmonate in the production of phenolic compounds in plant cell suspension cultures of Thevetia peruviana. Biotechnol Rep (Amst) 19:e00273. https://doi.org/10.1016/j.btre.2018.e00273

69. Mikulic-Petkovsek M, Usenik V, Stampar F (2003) The role of chlorogenic acid in the resistance of apples to apple scab (Venturia inaequalis (Cooke) G. Wind. Aderh.). Zb Bioteh Fak Univ Ljublj Kmet 81:233-242

70. Muñoz-Urias A, Palomino-Hasbach G, Terrazas T, García-Velázquez A, Pimienta-Barrios E (2008) Variación anatómica y morfológica en especies y entre poblaciones de Opuntia en la porción sur del Desierto Chihuahuense. Bol Soc Bot Mex 83:1-11. https://doi.org/10.17129/botsci.1784

71. Musil CF, Björn LO, Scourfield MWJ, Bodeker GE (2002) How substantial are ultraviolet-B supplementation inaccuracies in experimental square-wave delivery systems? Environ Exp Bot 47:25-38. https://doi.org/https://doi.org/10.1016/S0098-8472(01)00108-3

72. Naoumkina M, Dixon RA (2008) Subcellular localization of flavonoid natural products: A signaling function? Plant Signal Behav 3:573575. https://doi.org/10.4161/psb.3.8.5731

73. Nuessly GS, Scully BT, Hentz MG, Beiriger R, Snook ME, Widstrom NW (2007) Resistance to Spodoptera frugiperda (Lepidoptera: Noctuidae) and Euxesta stigmatias (Diptera: Ulidiidae) in sweet corn derived from exogenous and endogenous genetic systems. $J$ Econ Entomol 100:1887-1895. https://doi.org/10.1603/0022-0493(2007)100[1887:RTSFLN]2.0.CO;2

74. Padmavati M, Sakthivel N, Thara KV, Reddy AR (1997) Differential sensitivity of rice pathogens to growth inhibition by flavonoids. Phytochemistry 46:499-502. https://doi.org/10.1016/S0031-9422(97)00325-7

75. Parvez MM, Tomita-Yokotani K, Fujii Y, Konishi T, Iwashina T (2004) Effects of quercetin and its seven derivatives on the growth of Arabidopsis thaliana and Neurospora crassa. Biochem Syst Ecol 32:631-635. https://doi.org/10.1016/j.bse.2003.12.002

76. Peer WA, Brown DE, Tague BW, Muday GK, Taiz L, Murphy AS (2001) Flavonoid accumulation patterns of transparent testa mutants of arabidopsis. Plant Physiol 126:536-548. https://doi.org/10.1104/pp.126.2.536

77. Pelletier MK, Shirley BW (1996) Analysis of flavanone 3-hydroxylase in Arabidopsis seedlings. Coordinate regulation with chalcone synthase and chalcone isomerase. Plant Physiol 111:339-345. https://doi.org/10.1104/pp.111.1.339

Page 15/32 
78. Pierpoint WS (1994) Salicylic Acid and its Derivatives in Plants: Medicines, Metabolites and Messenger Molecules. Adv Bot Res 20:163235. https://doi.org/10.1016/S0065-2296(08)60217-7

79. Pieterse CM, Van der Does D, Zamioudis C, Leon-Reyes A, Van Wees SC (2012) Hormonal modulation of plant immunity. Annu Rev Cell Dev Biol 28:489-521. https://doi.org/10.1146/annurev-cellbio-092910-154055

80. Pinheiro J, Bates D, DebRoy S, Sarkar D, Team RC (2018) nlme: Linear and Nonlinear Mixed Effects Models. R package version 3.1-137. https://CRAN.R-project.org/package=nlme.

81. RCoreTeam (2020) R: A language and environment for statistical computing. R Foundation for Statistical Computing, Vienna, Austria

82. Rivas-San Vicente M, Plasencia J (2011) Salicylic acid beyond defence: its role in plant growth and development. J Exp Bot 62:33213338. https://doi.org/10.1093/jxb/err031

83. Rozema J, Bjorn LO, Bornman JF, Gaberscik A, Hader DP, Trost T, Germ M, Klisch M, Groniger A, Sinha RP, Lebert M, He YY, Buffoni-Hall R, de Bakker NV, van de Staaij J, Meijkamp BB (2002) The role of UV-B radiation in aquatic and terrestrial ecosystems--an experimental and functional analysis of the evolution of UV-absorbing compounds. J Photochem Photobiol B 66:2-12. https://doi.org/10.1016/S10111344(01)00269-X

84. RStudioTeam (2020) RStudio: Integrated Development Environment for R. . RStudio, PBC, Boston, MA

85. Russo A, Acquaviva R, Campisi A, Sorrenti V, Di Giacomo C, Virgata G, Barcellona ML, Vanella A (2000) Bioflavonoids as antiradicals, antioxidants and DNA cleavage protectors. Cell Biol Toxicol 16:91-98. https://doi.org/10.1023/a:1007685909018

86. Sandoval-Molina MA, Zavaleta-Mancera HA, Leon-Solano HJ, Solache-Ramos LT, Jenner B, Morales-Rodriguez S, Patron-Soberano A, Janczur MK (2018) First description of extrafloral nectaries in Opuntia robusta (Cactaceae): anatomy and ultrastructure. PLoS ONE 13:e0200422. https://doi.org/10.1371/journal.pone.0200422

87. SAS Institute Inc. (2016) Base SAS ${ }^{8} 9.4$ Procedures Guide. Cary, NC: SAS Institute Inc.,

88. SAS Institute Inc. (2017) SAS System for Windows, 9.4 edn. SAS Institute Inc.,

89. Saslowsky DE, Warek U, Winkel BS (2005) Nuclear localization of flavonoid enzymes in Arabidopsis. J Biol Chem 280:23735-23740. https://doi.org/10.1074/jbc.M413506200

90. Schmitz-Hoerner R, Weissenbock G (2003) Contribution of phenolic compounds to the UV-B screening capacity of developing barley primary leaves in relation to DNA damage and repair under elevated UV-B levels. Phytochemistry 64:243-255. https://doi.org/10.1016/s0031-9422(03)00203-6

91. Schnitzler JP, Madlung J, Rose A, Ulrich Seitz H (1992) Biosynthesis of p-hydroxybenzoic acid in elicitor-treated carrot cell cultures. Planta 188:594-600. https://doi.org/10.1007/BF00197054

92. Schweiger R, Heise AM, Persicke M, Müller C (2014) Interactions between the jasmonic and salicylic acid pathway modulate the plant metabolome and affect herbivores of different feeding types. Plant, Cell Environ 37:1574-1585. https://doi.org/10.1111/pce.12257

93. SEMARNAT (2010) Norma Oficial Mexicana NOM-059-SEMARNAT-2010, Protección ambiental-Especies nativas de México de flora y fauna silvestres-Categorías de riesgo y especificaciones para su inclusión, exclusión o cambio-Lista de especies en riesgo. Secretaria de Medio Ambiente y Recursos Naturales (SEMARNAT), Mexico

94. SEMARNAT (2013) Áreas naturales protegidas: diagnóstico final. Secretaria de Medio Ambiente y Recursos Naturales (SEMARNAT), México

95. Sharma S, Chatterjee S, Kataria S, Joshi J, Datta S, Vairale MG, Veer V (2017) A Review on responses of plants to UV-B radiation related stress. In: UV-B Radiation. pp 75-97. https://doi.org/10.1002/9781119143611.ch5

96. Skogsmyr I, Fagerstrom T (1992) The cost of antiherbivory defence - An evaluation of some ecological and physiological factors. Oikos 64:451-457. https://doi.org/10.2307/3545160

97. Smith-Becker J, Marois E, Huguet EJ, Midland SL, Sims JJ, Keen NT (1998) Accumulation of salicylic acid and 4-hydroxybenzoic acid in phloem fluids of cucumber during systemic acquired resistance is preceded by a transient increase in phenylalanine ammonia-lyase activity in petioles and stems. Plant Physiol 116:231-238. https://doi.org/10.1104/pp.116.1.231

98. Solovchenko A, Schmitz-Eiberger M (2003) Significance of skin flavonoids for UV-B-protection in apple fruits. J Exp Bot 54:1977-1984. https://doi.org/10.1093/jxb/erg199

99. Sperandei S (2014) Understanding logistic regression analysis. Biochem Med (Zagreb) 24:12-18. https://doi.org/10.11613/BM.2014.003

100. Strauss SY, Rudgers JA, Lau JA, Irwin RE (2002) Direct and ecological costs of resistance to herbivory. Trends Ecol Evol 17:278-285. https://doi.org/10.1016/S0169-5347(02)02483-7

101. Sudha G, Ravishankar GA (2003) Elicitation of anthocyanin production in callus cultures of Daucus carota and the involvement of methyl jasmonate and salicylic acid. Acta Physiol Plant 25:249-256. https://doi.org/10.1007/s11738-003-0005-4 
102. Takanaga H, Tamai I, Tsuji A (1994) pH-Dependent and Carrier-mediated Transport of Salicylic Acid Across Caco-2 Cells. J Pharm Pharmacol 46:567-570. https://doi.org/10.1111/j.2042-7158.1994.tb03858.x

103. Tan J, Bednarek P, Liu J, Schneider B, Svatos A, Hahlbrock K (2004) Universally occurring phenylpropanoid and species-specific indolic metabolites in infected and uninfected Arabidopsis thaliana roots and leaves. Phytochemistry 65:691-699. https://doi.org/10.1016/j.phytochem.2003.12.009

104. Tuan PA, Kwon DY, Lee S, Arasu MV, Al-Dhabi NA, Park NI, Park SU (2014) Enhancement of chlorogenic acid production in hairy roots of Platycodon grandiflorum by over-expression of an Arabidopsis thaliana transcription factor AtPAP1. Int J Mol Sci 15:14743-14752. https://doi.org/10.3390/ijms150814743

105. Ulmasov T, Hagen G, Guilfoyle T (1994) The ocs element in the soybean GH2/4 promoter is activated by both active and inactive auxin and salicylic acid analogues. Plant Mol Biol 26:1055-1064. https://doi.org/10.1007/BF00040688

106. van Dam NM, Verpoorte R, van der Meijden E (1994) Extreme differences in pyrrolizidine alkaloid levels between leaves of Cynoglossum officinale. Phytochemistry 37:1013-1016. https://doi.org/10.1016/S0031-9422(00)89519-9

107. van Velzen E, Etienne RS (2015) The importance of ecological costs for the evolution of plant defense against herbivory. J Theor Biol 372:89-99. https://doi.org/10.1016/j.jtbi.2015.02.027

108. Waller GR, Nowacki EK (1978) Alkaloid biology and metabolism in plants. Plenum Press., New York

109. Wang J, Zhao X-H (2016) Degradation kinetics of fisetin and quercetin in solutions affected by medium $\mathrm{pH}$, temperature and co-existed proteins. J Serb Chem Soc 81:243-253. https://doi.org/10.2298/JSC150706092W

110. War AR, Paulraj MG, Ahmad T, Buhroo AA, Hussain B, Ignacimuthu S, Sharma HC (2012) Mechanisms of plant defense against insect herbivores. Plant Signal Behav 7:1306-1320. https://doi.org/10.4161/psb.21663

111. War AR, Paulraj MG, War MY, Ignacimuthu S (2011) Role of salicylic acid in induction of plant defense system in chickpea (Cicer arietinum L.). Plant Signal Behav 6:1787-1792. https://doi.org/10.4161/psb.6.11.17685

112. Warabieda W, Miszczak A, Olszak RW (2005) The influence of methyl jasmonate (JA-Me) and B-glucosidase on induction of resistance mechanisms of strawberry against two-spotted spider mite (Tetranychus urticae Koch.). Commun Agric Appl Biol Sci 70:829-836

113. Warton DI, Wright IJ, Falster DS, Westoby M (2006a) Bivariate line-fitting methods for allometry. Biol Rev 81:259-291. https://doi.org/10.1017/s1464793106007007

114. Warton DI, Wright IJ, Falster DS, Westoby M (2006b) Bivariate line-fitting methods for allometry. Biol Rev Camb Philos Soc 81:259-291. https://doi.org/10.1017/S1464793106007007

115. Wilson KE, Wilson MI, Greenberg BM (1998) Identification of the flavonoid glycosides that accumulate in Brassica napus L. cv. Topas specifically in response to ultraviolet B radiation. Photochem Photobiol 67:547-553. https://doi.org/10.1111/j.1751-1097.1998.tb09092.x

116. Wuyts N, Swennen R, De Waele D (2006) Effects of plant phenylpropanoid pathway products and selected terpenoids and alkaloids on the behaviour of the plant-parasitic nematodes Radopholus similis, Pratylenchus penetrans and Meloidogyne incognita. Nematology 8:89-101. https://doi.org/10.1163/156854106776179953

117. Yuan S, Lin HH (2008) Role of salicylic acid in plant abiotic stress. Z Naturforsch C J Biosci 63:313-320. https://doi.org/10.1515/znc2008-5-601

\section{Tables}

Table 1. THE EFFECT OF SAMPLING MONTH AND OF CLADODE AGE ESTIMATORS OF HERMAPHRODITE CLADODES OF O. robusta ON THE PROBABILITY OF DETECTION OF 4-HYDROBENZOIC ACID (4-HBA), CHLOROGENIC ACID (CGA), AND QUERCETIN (QUE) IN THE LOGISTIC REGRESSION AND MIXED EFFECT GENERALIZED LINEAR MODELS; DF - THE NUMBER OF DEGREES OF FREEDOM IN THE MODEL. EST THE EFFECT OF THE MODEL ESTIMATOR, SE - STANDARD ERROR OF THE ESTIMATOR, $P$ - PROBABILITY OF THE PREDICTOR

a) THE EFFECT OF SAMPLING MONTH ON THE PROPORTION OF CLADODES BEARING 4-HYDROXYBENZOIC ACID, CHLOROGENIC ACID, AND QUERCETIN 


\begin{tabular}{|c|c|c|c|c|c|c|c|c|c|c|c|c|c|}
\hline \multicolumn{4}{|c|}{ 4-hydroxybenzoic acid } & \multicolumn{4}{|c|}{ Chlorogenic acid } & \multicolumn{3}{|c|}{ Quercetin } & \multirow[b]{2}{*}{ SE } & \multirow[b]{2}{*}{ Stat } & \multirow[b]{2}{*}{$\mathrm{P}$} \\
\hline Predictors & Est & SE & Stat & $P$ & & Est & SE & Stat & $P$ & Est & & & \\
\hline (Intercept) & 0.187 & 0.018 & 10.12 & $<0.0$ & & 0.104 & 0.009 & 11.21 & $<0.001$ & 0.009 & 0.002 & 4.40 & $<0.001$ \\
\hline April & -0.042 & 0.025 & -1.66 & 0.10 & & 0.011 & 0.013 & 0.82 & 0.42 & 0.151 & 0.003 & 52.78 & $<0.001$ \\
\hline May & -0.049 & 0.025 & -1.96 & 0.05 & & 0.048 & 0.013 & 3.74 & $<0.001$ & 0.033 & 0.003 & 11.55 & $<0.001$ \\
\hline June & -0.002 & 0.026 & -0.06 & 0.95 & & -0.019 & 0.013 & -1.47 & 0.15 & 0.052 & 0.003 & 18.27 & $<0.001$ \\
\hline July & -0.103 & 0.026 & -3.95 & $<0.0$ & & -0.003 & 0.013 & -0.26 & 0.79 & 0.031 & 0.003 & 10.92 & $<0.001$ \\
\hline August & -0.118 & 0.025 & -4.66 & $<0.0$ & & 0.077 & 0.013 & 5.950 & $<0.001$ & 0.058 & 0.003 & 20.41 & $<0.001$ \\
\hline September & -0.154 & 0.025 & -6.20 & $<0.0$ & & -0.041 & 0.013 & -3.18 & $<0.001$ & 0.007 & 0.003 & 2.58 & 0.01 \\
\hline October & -0.012 & 0.025 & -0.482 & 0.63 & & 0.025 & 0.013 & 1.94 & 0.06 & 0.136 & 0.003 & 47.81 & $<0.001$ \\
\hline \multicolumn{3}{|c|}{ Observations } & 283 & \multicolumn{4}{|c|}{283} & & & \multicolumn{2}{|l|}{283} & & \\
\hline \multicolumn{3}{|c|}{ Marginal $\mathrm{R}^{2}$ /Conditional $\mathrm{R}^{2}$} & $0.491 /$ & \multicolumn{4}{|c|}{$0.615 / 1.000$} & & & \multicolumn{2}{|c|}{$0.987 / 1.000$} & & \\
\hline \multicolumn{3}{|l|}{ AIC } & -15603. & \multicolumn{4}{|c|}{-15732.724} & & & \multicolumn{2}{|c|}{-16178.202} & & \\
\hline \multicolumn{3}{|c|}{ log-Likelihood } & 7811.71 & & \multicolumn{2}{|c|}{7876.362} & & & & \multicolumn{2}{|c|}{8099.101} & & \\
\hline
\end{tabular}

b) THE EFFECT OF THE CLADODE ORDER COUNTED FROM SOIL ON THE PROPORTION OF CLADODES BEARING 4-HYDROXYBENZOIC ACID, CHLOROGENIC ACID, AND QUERCETIN

\begin{tabular}{|c|c|c|c|c|c|c|c|c|c|c|c|c|}
\hline \multicolumn{4}{|c|}{ 4-hydroxybenzoic acid } & \multicolumn{3}{|c|}{ Chlorogenic acid } & \multicolumn{3}{|c|}{ Quercetin } & \multirow[b]{2}{*}{ SE } & \multirow[b]{2}{*}{ Stat } & \multirow[b]{2}{*}{$\mathrm{P}$} \\
\hline Predictors & Est & SE & Stat & $P$ & Est & SE & Stat & $\mathrm{P}$ & Est & & & \\
\hline (Intercept) & 0.067 & 0.008 & 8.768 & $<0.001$ & -0.085 & 0.015 & -5.763 & $<0.001$ & 0.082 & 0.003 & 24.374 & $<0.001$ \\
\hline Cladode Order & 0.027 & 0.001 & 40.818 & $<0.001$ & 0.080 & 0.004 & 20.331 & $<0.001$ & -0.011 & 0.0005 & -32.988 & $<0.001$ \\
\hline \multicolumn{3}{|l|}{ Observations } & \multicolumn{2}{|l|}{283} & \multicolumn{4}{|l|}{283} & \multicolumn{4}{|l|}{283} \\
\hline \multicolumn{3}{|c|}{ Marginal $\mathrm{R}^{2}$ /Conditional $\mathrm{R}^{2}$} & \multicolumn{2}{|c|}{$0.193 / 0.969$} & \multicolumn{4}{|c|}{$0.402 / 0.738$} & \multicolumn{4}{|c|}{$0.162 / 0.960$} \\
\hline \multicolumn{3}{|l|}{ AIC } & \multicolumn{2}{|c|}{-1311.853} & \multicolumn{4}{|c|}{-509.762} & \multicolumn{4}{|c|}{-1730.600} \\
\hline \multicolumn{3}{|l|}{ log-Likelihood } & \multicolumn{2}{|l|}{659.927} & \multicolumn{4}{|c|}{258.881} & \multicolumn{4}{|c|}{869.300} \\
\hline
\end{tabular}

c) THE EFFECT OF THE NUMBER OF CLADODES ABOVE A GIVEN CLADODE OF ANY ORDER COUNTED FROM SOIL ON THE PROPORTION OF CLADODES BEARING 4-HYDROXYBENZOIC ACID, CHLOROGENIC ACID, AND QUERCETIN

\begin{tabular}{|c|c|c|c|c|c|c|c|c|c|c|c|c|}
\hline \multicolumn{4}{|c|}{ 4-hydroxybenzoic acid } & \multicolumn{3}{|c|}{ Chlorogenic acid } & \multicolumn{3}{|c|}{ Quercetin } & \multirow[b]{2}{*}{ SE } & \multirow[b]{2}{*}{ Stat } & \multirow[b]{2}{*}{$\mathrm{P}$} \\
\hline Predictors & Est & SE & Stat & $P$ & Est & SE & Stat & $\mathrm{P}$ & Est & & & \\
\hline (Intercept) & 0.184 & 0.007 & 26.24 & $<0.001$ & 0.245 & 0.011 & 23.37 & $<0.001$ & 0.039 & 0.003 & 12.31 & $<0.001$ \\
\hline Cladodes above & -0.032 & 0.001 & -42.94 & $<0.001$ & -0.087 & 0.004 & -22.18 & $<0.001$ & 0.011 & 0.0005 & 32.75 & $<0.001$ \\
\hline \multicolumn{3}{|l|}{ Observations } & \multicolumn{2}{|l|}{283} & \multicolumn{4}{|l|}{283} & \multicolumn{4}{|l|}{283} \\
\hline \multicolumn{3}{|c|}{ Marginal $\mathrm{R}^{2} /$ Conditional $\mathrm{R}^{2}$} & \multicolumn{2}{|c|}{$0.281 / 0.959$} & \multicolumn{4}{|c|}{$0.511 / 0.719$} & \multicolumn{4}{|c|}{$0.184 / 0.954$} \\
\hline \multicolumn{3}{|l|}{ AIC } & \multicolumn{2}{|c|}{-1273.883} & \multicolumn{4}{|c|}{-544.413} & \multicolumn{4}{|c|}{-1719.035} \\
\hline \multicolumn{3}{|l|}{ log-Likelihood } & \multicolumn{2}{|c|}{640.941} & \multicolumn{4}{|c|}{276.206} & \multicolumn{4}{|c|}{863.518} \\
\hline
\end{tabular}


TABLE 2. RESULTS OF GENERALIZED LINEAR MIXED MODEL OF THE EFFECT OF BRANCH TYPE (TREATMENT), CLADODE CONDITION (COVERED/UNCOVERED), AND DAYTIME, ON THE PH OF THE HERMAPHRODITE CLADODES OF O. robusta: SIGNIFICANCE LEVELS OF MAIN EFFECTS AND OF DIFFERENT BRANCH TYPE, OR EXPERIMENTAL TREATMENT (COVERED/UNCOVERED CLADODES). BRANCH TYPES (TREATMENTS): 1 - UNCOVERED APICAL CLADODE, COVERED BASAL CLADODE, 2 - COVERED APICAL CLADODES, UNCOVERED BASAL CLADODE, 3 - UNCOVERED APICAL AND BASAL CLADODES, AND 4 - COVERED APICAL AND BASAL CLADODES. DEN DF - DEGREES OF FREEDOM ASSOCIATED TO THE ERROR TERM

\begin{tabular}{|lllll|}
\hline \multicolumn{5}{|l|}{ Type III tests of fixed effects } \\
\hline Effect & DF & Den DF & F & P \\
\hline Treatment & 3 & 19.09 & 0.33 & 0.8012 \\
\hline Covered $(\mathbf{y} / \mathbf{n})$ & 1 & 110.7 & 0.04 & 0.8440 \\
\hline Time & 4 & 118.5 & 20.96 & $<0.001$ \\
\hline
\end{tabular}

TABLE 3. THE EFFECT OF SHADING AND CLADODE POSITION (APICAL, BASAL) ON THE CONCENTRATIONS OF 4-HYDROXYBENZOIC ACID (4-HBA) OR CHLOROGENIC ACID (CGA), OR ON THE PROPORTION OF CLADODES BEARING QUERCETINE (QUE) OR SALICYLIC ACID (SA). WE ANALYZED THE PROPORTIONS OF QUE AND SA INSTEAD OF THEIR CONCENTRATION, BECAUSE ONLY FEW CLADODES CONTAINED THEM. IN A), B) and C)

a) PROBABILITY POF F IN THE ANALYSIS OF VARIANCE

\begin{tabular}{|lllll|}
\hline Effect & $P(\mathrm{~F})$ 4-HBA & $P(\mathrm{~F}) \mathrm{CGA}$ & $P(\mathrm{~F})$ QUE & $P(\mathrm{~F}) \mathrm{SA}$ \\
\hline Treatment & 0.9685 & 0.2925 & 0.7901 & 0.9192 \\
\hline Condition & 0.9030 & 0.4436 & $\mathbf{0 . 0 1 2 6}$ & 0.4828 \\
\hline Treatment $\times$ condition & 0.2819 & 0.5699 & 0.8607 & 0.5251 \\
\hline
\end{tabular}

SIGNIFICANT EFFECTS AT P $\leq 0.05$ ARE MARQUED WITH BOLD

b) CONFIDENCE INTERVALS FOR ADJUSTED MEANS (MU; LSM=LEAST SQUARES MEANS), FOR ALL COMBINATIONS AMONG TREATMENTS AND CLADODE LEVELS, FOR 4-HYDROXYBENZOIC ACID (4-HBA), CHLOROGENIC ACID, QUERCETIN AND SALICYLIC ACID

\begin{tabular}{|lllllllllllllll|}
\hline \multicolumn{4}{l}{ 4-hydroxybenzoic acid } & \multicolumn{4}{c}{ Chlorogenic acid } & \multicolumn{3}{c}{ Quercetin } & \multicolumn{4}{c|}{ Salicylic acid } \\
\hline Treat & Cond & $\mathbf{M u}$ & $-\mathrm{Mu}$ & $+\mathrm{Mu}$ & $\mathrm{Mu}$ & $-\mathrm{Mu}$ & $+\mathrm{Mu}$ & $\mathrm{Mu}$ & $-\mathrm{Mu}$ & $+\mathrm{Mu}$ & $\mathrm{Mu}$ & $-\mathrm{Mu}$ & $+\mathrm{Mu}$ \\
\hline light & - & 16673 & 8836.36 & 24510 & 14661 & 10534 & 18789 & 0.096 & 0.0323 & 0.2520 & 0.0792 & 0.0230 & 0.2390 \\
\hline shade & - & 16525 & 8688.42 & 24362 & 12248 & 8120.3 & 16375 & 0.116 & 0.0405 & 0.2895 & 0.0847 & 0.0256 & 0.2462 \\
\hline- & apical & 16371 & 8534.39 & 24208 & 14331 & 10204 & 18459 & 0.041 & 0.0099 & 0.1548 & 0.1032 & 0.0331 & 0.2787 \\
\hline- & basal & 16827 & 8990.39 & 24664 & 12578 & 8450.4 & 16705 & 0.246 & 0.1363 & 0.4018 & 0.0647 & 0.0177 & 0.2097 \\
\hline light & apical & 19545 & 9493.46 & 29596 & 16196 & 11078 & 21314 & 0.040 & 0.0053 & 0.2412 & 0.1226 & 0.0320 & 0.3712 \\
\hline light & basal & 13801 & 3387.10 & 24215 & 13127 & 7845.5 & 18408 & 0.214 & 0.0883 & 0.4344 & 0.0503 & 0.0083 & 0.2515 \\
\hline shade & apical & 13197 & 2783.15 & 23611 & 12466 & 7185.4 & 17747 & 0.042 & 0.0057 & 0.2555 & 0.0865 & 0.0187 & 0.3202 \\
\hline shade & basal & 19853 & 9801.53 & 29904 & 12029 & 6911.2 & 17147 & 0.280 & 0.1342 & 0.4933 & 0.0829 & 0.0182 & 0.3067 \\
\hline
\end{tabular}

c) PAIRWISE COMPARISONS FOR ALL COMBINATION OF TREATMENTS (SHADED AND LIGHTED CLADODES) AND CLADODE POSITIONS (APICAL, BASAL), RESPECTIVE PROBABILITIES, LSM (LEAST SQUARES MEANS) ESTIMATE AND CONFIDENCE INTERVALS FOR THE LSM DIFFERENCE BETWEEN VALUES FOR THE COMBINATIONS OF APICAL, BASAL, SHADED AND LIGHTED CLADODES 


\begin{tabular}{|c|c|c|c|c|c|c|c|}
\hline Treatment & Condition & _treatment & _Condition & $P(t)$ & Estimate & Lower & Upper \\
\hline \multicolumn{8}{|c|}{ 4-HYDROXYBENZOIC ACID } \\
\hline light & - & shade & - & 0.97 & 147.94 & -7340.96 & 7636.83 \\
\hline- & apical & - & basal & 0.90 & -456.00 & -7944.90 & 7032.89 \\
\hline light & apical & light & basal & 0.40 & 5743.44 & -7846.81 & 19334 \\
\hline light & apical & shade & apical & 0.35 & 6347.38 & -7242.87 & 19938 \\
\hline light & apical & shade & basal & 0.95 & -308.07 & -10676 & 10060 \\
\hline light & basal & shade & apical & 0.91 & 603.94 & -10205 & 11413 \\
\hline light & basal & shade & basal & 0.37 & -6051.51 & -19642 & 7538.75 \\
\hline $\begin{array}{l}\text { shade } \\
\text { CHLOROGE }\end{array}$ & \multicolumn{6}{|c|}{ CHLOROGENIC ACID } & 6934.81 \\
\hline light & - & shade & - & 0.29 & 2413.48 & -2125.90 & 6952.86 \\
\hline- & apical & - & basal & 0.44 & 1753.37 & -2786.01 & 6292.75 \\
\hline light & apical & light & basal & 0.35 & 3069.53 & -3391.14 & 9530.19 \\
\hline light & apical & shade & apical & 0.25 & 3729.64 & -2731.02 & 10190 \\
\hline light & apical & shade & basal & 0.19 & 4166.85 & -2117.63 & 10451 \\
\hline light & basal & shade & apical & 0.84 & 660.11 & -5891.92 & 7212.14 \\
\hline light & basal & shade & basal & 0.74 & 1097.32 & -5363.34 & 7557.99 \\
\hline $\begin{array}{l}\text { shade } \\
\text { QUERCETIN }\end{array}$ & apical & shade & basal & 0.89 & 437.21 & -6023.45 & 6897.88 \\
\hline light & - & shade & - & 0.79 & -0.2131 & -1.7982 & 1.3721 \\
\hline - & apical & - & basal & 0.01 & -2.0304 & -3.6159 & -0.4450 \\
\hline light & apical & light & basal & 0.10 & -1.8896 & -4.1572 & 0.3779 \\
\hline light & apical & shade & apical & 0.96 & -0.07228 & -2.9459 & 2.8013 \\
\hline light & apical & shade & basal & 0.047 & -2.2435 & -4.4584 & -0.02862 \\
\hline light & basal & shade & apical & 0.11 & 1.8174 & -0.4513 & 4.0860 \\
\hline light & basal & shade & basal & 0.60 & -0.3539 & -1.7019 & 0.9941 \\
\hline $\begin{array}{l}\text { shade } \\
\text { SALICYLIC }\end{array}$ & \multicolumn{6}{|c|}{ SALICYLIC ACID } & 0.05010 \\
\hline light & - & shade & - & 0.92 & -0.07313 & -1.5008 & 1.3545 \\
\hline- & apical & - & basal & 0.48 & 0.5083 & -0.9243 & 1.9409 \\
\hline light & apical & light & basal & 0.36 & 0.9704 & -1.1108 & 3.0516 \\
\hline light & apical & shade & apical & 0.68 & 0.3890 & -1.4915 & 2.2694 \\
\hline light & apical & shade & basal & 0.64 & 0.4352 & -1.4299 & 2.3002 \\
\hline light & basal & shade & apical & 0.60 & -0.5814 & -2.7500 & 1.5872 \\
\hline light & basal & shade & basal & 0.62 & -0.5352 & -2.6983 & 1.6278 \\
\hline shade & apical & shade & basal & 0.96 & 0.04621 & -1.9316 & 2.0240 \\
\hline
\end{tabular}


TABLE 4. THE COEFFICIENTS OF THE STANDARDIZED MAJOR AXES (SMA) FOR THE RELATIONSHIP BETWEEN THE CONCENTRATIONS OF SECONDARY METABOLITES, COMPARISON AMONG SLOPES, CONFIDENCE LIMITS FOR THESE COEFFICIENTS, PROPORTION OF THE VARIANCE EXPLAINED BY THE MODEL $\left(\mathrm{R}^{2}\right)$, AND THE PROBABILITY FOR THE SIGNIFICANCE TEST ( $P$ ). 4-HBA - 4-HYDROXYBENZOIC ACID, CGA - CHLOROGENIC ACID, QUE - QUERCETIN, AND SA - SALICYLIC ACID. 


\begin{tabular}{|c|c|c|c|c|c|c|c|c|c|c|c|}
\hline SM1 & SM2 & Treat. & Group & Intercept & $-\mathrm{Cl}$ & $+\mathrm{Cl}$ & Slope & $-\mathrm{Cl}$ & $+\mathrm{Cl}$ & $\mathrm{R}^{2}$ & $\mathbf{P}$ \\
\hline 4-HBA & SA & Light & a & 2189.18 & 48.14 & 4330.2 & 0.28 & 0.12 & 0.65 & 0.75 & 0.058 \\
\hline 4-HBA & SA & Shade & b & -1392.1 & -10475.4 & 7691.2 & 0.95 & 0.30 & 3.01 & 0.39 & 0.26 \\
\hline 4-HBA & SA & Pooled & $a b$ & 1328.94 & -867.32 & 3525.19 & 0.46 & 0.26 & 0.83 & 0.41 & 0.047 \\
\hline 4-HBA & SA & Apical & a & 2055.7 & -1443.52 & 5554.84 & 0.40 & 0.15 & 1.02 & 0.36 & 0.21 \\
\hline 4-HBA & SA & Basal & $a$ & -453.1 & -7473.6 & 6567.5 & 0.68 & 0.20 & 2.28 & 0.75 & 0.13 \\
\hline 4-HBA & SA & Pooled & $a$ & 1328.9 & -867.32 & 3525.19 & 0.46 & 0.26 & 0.83 & 0.41 & 0.047 \\
\hline 4-HBA & CGA & Light & $\mathrm{a}$ & 8291.3 & 3931.2 & 12651.3 & 0.38 & 0.29 & 0.51 & 0.03 & 0.22 \\
\hline 4-HBA & CGA & Shade & $a$ & 2487.4 & -2637.0 & 7611.9 & 0.49 & 0.37 & 0.66 & 0.01 & 0.56 \\
\hline 4-HBA & CGA & Pooled & $a$ & 5426.9 & 2119.0 & 8734.8 & 0.44 & 0.36 & 0.54 & 0.02 & 0.20 \\
\hline 4-HBA & CGA & Apical & $\mathrm{a}$ & 6798.6 & 2270.4 & 11326.8 & 0.46 & 0.35 & 0.60 & 0.14 & 0.008 \\
\hline 4-HBA & CGA & Basal & a & 17968.9 & 14094.7 & 21843.2 & -0.39 & -0.52 & -0.29 & 0.06 & 0.095 \\
\hline \multirow[t]{2}{*}{ 4-HBA } & CGA & Pooled & a & 5426.9 & 2119.0 & 8734.8 & 0.44 & 0.36 & 0.54 & 0.02 & 0.20 \\
\hline & & Apical & & & & & & & & & \\
\hline 4-HBA & CGA & Light & a & 9644.4 & 3873.2 & 15415.6 & 0.33 & 0.22 & 0.49 & 0.13 & 0.08 \\
\hline 4-HBA & CGA & Shade & b & 2574.6 & -4924.9 & 10074.2 & 0.75 & 0.51 & 1.12 & 0.21 & 0.03 \\
\hline \multirow[t]{2}{*}{ 4-HBA } & CGA & Pooled & a & 6482.4 & 2166.6 & 10798.2 & 0.44 & 0.34 & 0.58 & 0.17 & 0.003 \\
\hline & & Basal & & & & & & & & & \\
\hline 4-HBA & CGA & Light & a & 20200.0 & 13675.9 & 26724.1 & -0.50 & -0.77 & -0.32 & 0.03 & 0.40 \\
\hline 4-HBA & CGA & Shade & $\mathrm{a}$ & 15386.7 & 10543.8 & 20229.7 & -0.3 & -0.46 & -0.20 & 0.08 & 0.19 \\
\hline 4-HBA & CGA & Pooled & a & 17267.6 & 13502.0 & 21033.3 & -0.37 & -0.50 & -0.28 & 0.06 & 0.10 \\
\hline CGA & SA & Light & a & 7844.6 & 3184.2 & 12505.0 & -0.45 & -1.24 & -0.17 & 0.27 & 0.29 \\
\hline CGA & SA & Shade & a & 6461.8 & 1626.2 & 11297.4 & -0.32 & -1.14 & -0.09 & 0.20 & 0.45 \\
\hline CGA & SA & Pooled & $\mathrm{a}$ & 7178.5 & 4873.3 & 9483.7 & -0.39 & -0.72 & -0.21 & 0.22 & 0.14 \\
\hline CGA & SA & Apical & a & 17492.1 & 3480.5 & 31503.6 & -4.23 & -11.08 & -1.62 & 0.05 & 0.61 \\
\hline CGA & SA & Basal & b & 7255.8 & -114.3 & 14625.8 & -0.28 & -1.17 & -0.07 & 0.59 & 0.23 \\
\hline \multirow[t]{2}{*}{ CGA } & SA & Pooled & b & 7178.5 & 4873.3 & 9483.7 & -0.39 & -0.72 & -0.21 & 0.22 & 0.14 \\
\hline & & Basal & & & & & & & & & \\
\hline 4-HBA & QUE & Light & a & 7331,6 & -49.3 & 14712.5 & $-0,08$ & -0.3 & -0.02 & 0.07 & 0.7 \\
\hline 4-HBA & QUE & Shade & a & 5690 & 1888.0 & 9493.0 & -0.07 & -0.21 & -0.02 & 0.03 & 0.7 \\
\hline \multirow[t]{2}{*}{ 4-HBA } & QUE & Pooled & a & 6294 & 3779.0 & 8809.0 & $-0,08$ & -0.15 & -0.04 & 0.03 & 0.6 \\
\hline & & Basal & & & & & & & & & \\
\hline CGA & QUE & Light & a & 1342.9 & -6459.7 & 9145.4 & 0.23 & 0.07 & 0.83 & 0.21 & 0.44 \\
\hline CGA & QUE & Shade & b & 17132.9 & 2335.9 & 31929.8 & -1.20 & -3.14 & -0.46 & 0.05 & 0.62 \\
\hline CGA & QUE & Pooled & $\mathbf{a}$ & 1503.7 & -857.9 & 3865.2 & 0.24 & 0.13 & 0.43 & 0.19 & 0.15 \\
\hline
\end{tabular}

SIGNIFICANT DIFFERENCES IN SLOPES AT P $\leq 0.05$ ARE MARQUED WITH BOLD. SM1 AND SM2 - SECONDARY METABOLITS USED IN THE SMA REGRESSION, GROUP - GROUPS SEPARATED IN THE COMPARISONS OF SLOPES OF THE SMA REGRESSIONS, TREAT. -

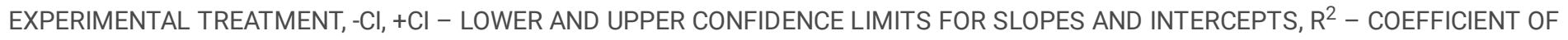
DETERMINATION OF EACH SMA EQUATIONS, P - PROBABILITY OF ADJUSTMENT OF ESTIMATION OF EACH SMA EQUATION. 
Figures
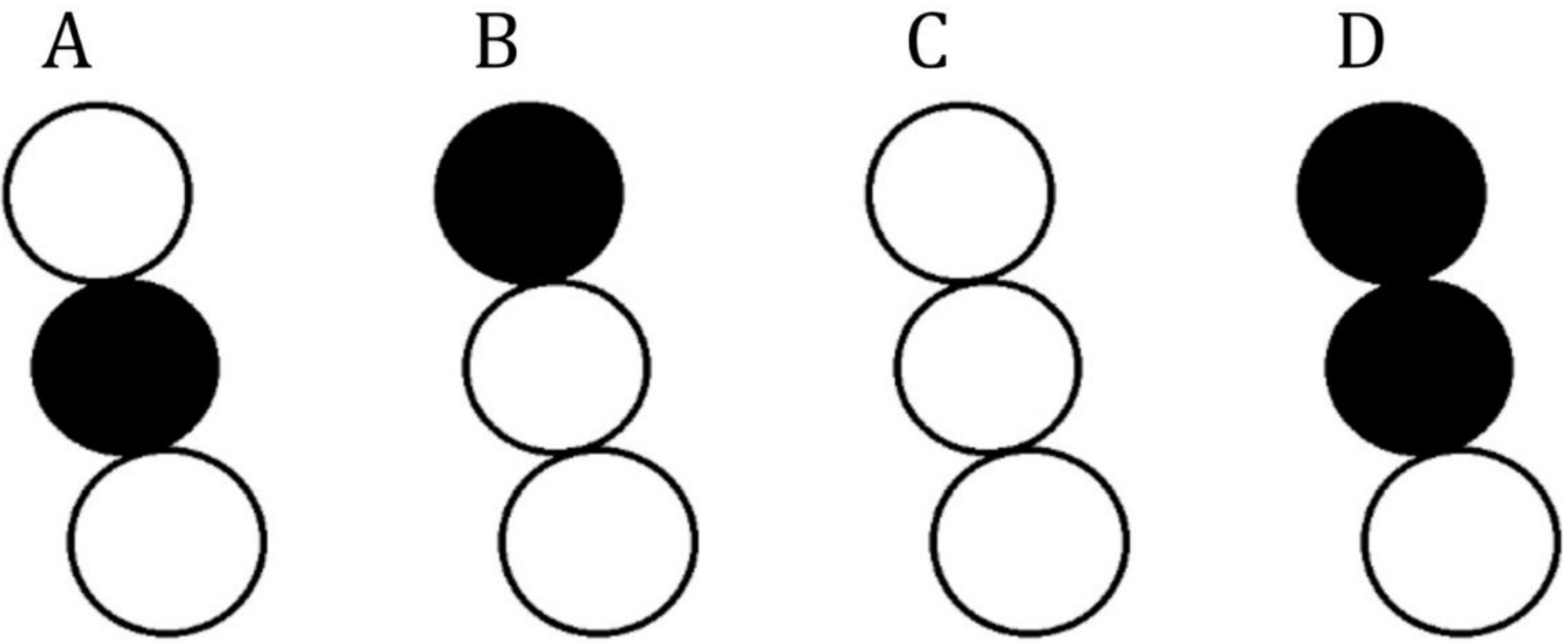

Figure 1

A scheme of the experiment with covered (shaded) and uncovered (lighted) cladodes. a) through d) were used to estimate the effect of shading on the $\mathrm{pH}$ of the vegetative tissue. a) and b) were used in the experiment concerning the effect of shading and of cladodes position, on the concentration or the probability of detection of the secondary metabolites

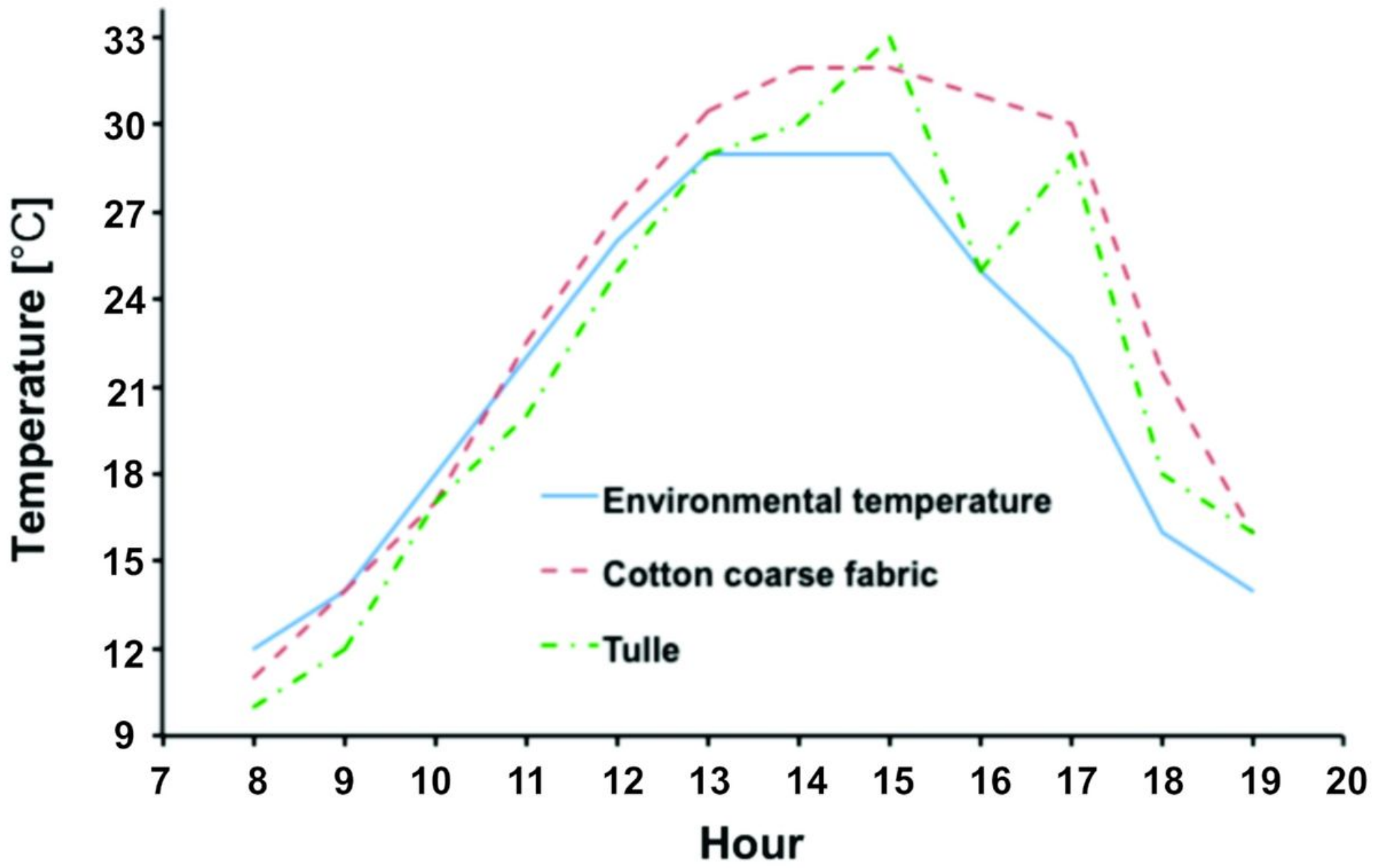

Figure 2 
The effect of shading fabric on cladode temperature - The paired t-test showed significant differences between the temperatures of noncovered cladodes and cladodes covered with black cotton coarse fabric $(t=2.88, P=0.015)$, and non-significant differences between the temperatures of non-covered cladodes and cladodes covered with black cotton coarse fabric lined with white tulle ( $\mathrm{t}=0.84, \mathrm{P}=0.42)$ : we used the black cotton coarse fabric lined with white tulle for field experiment
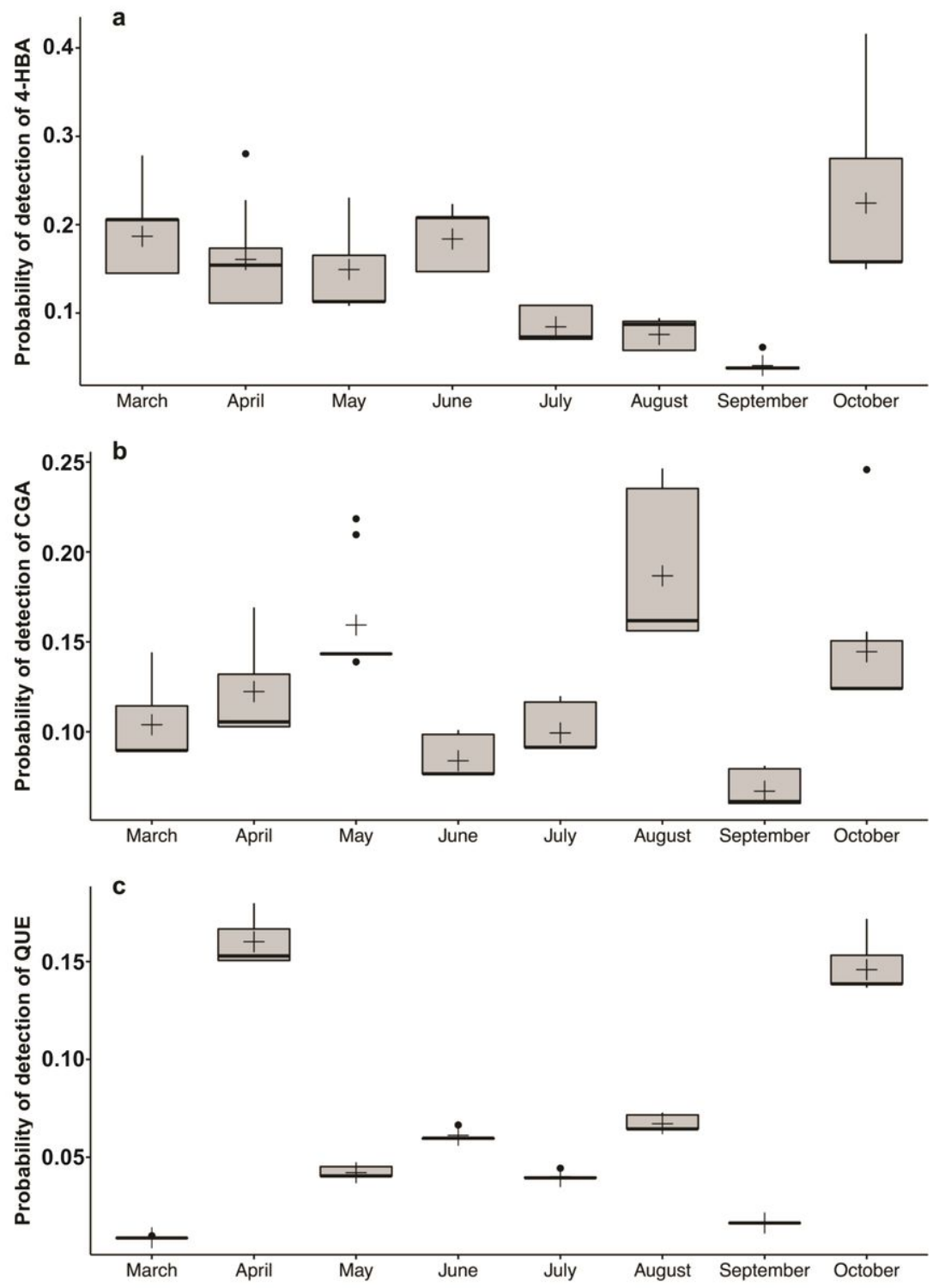

\section{Figure 3}

Monthly dynamics of the proportion of cladodes bearing a) 4-hydroxybenzoic acid (4-HBA), b) chlorogenic acid (CGA), and c) quercetin (QUE) in the vegetative tissue of hermaphrodite cladodes. The dynamics of the three secondary metabolites were significant at P < 0.001 in GLMM model 

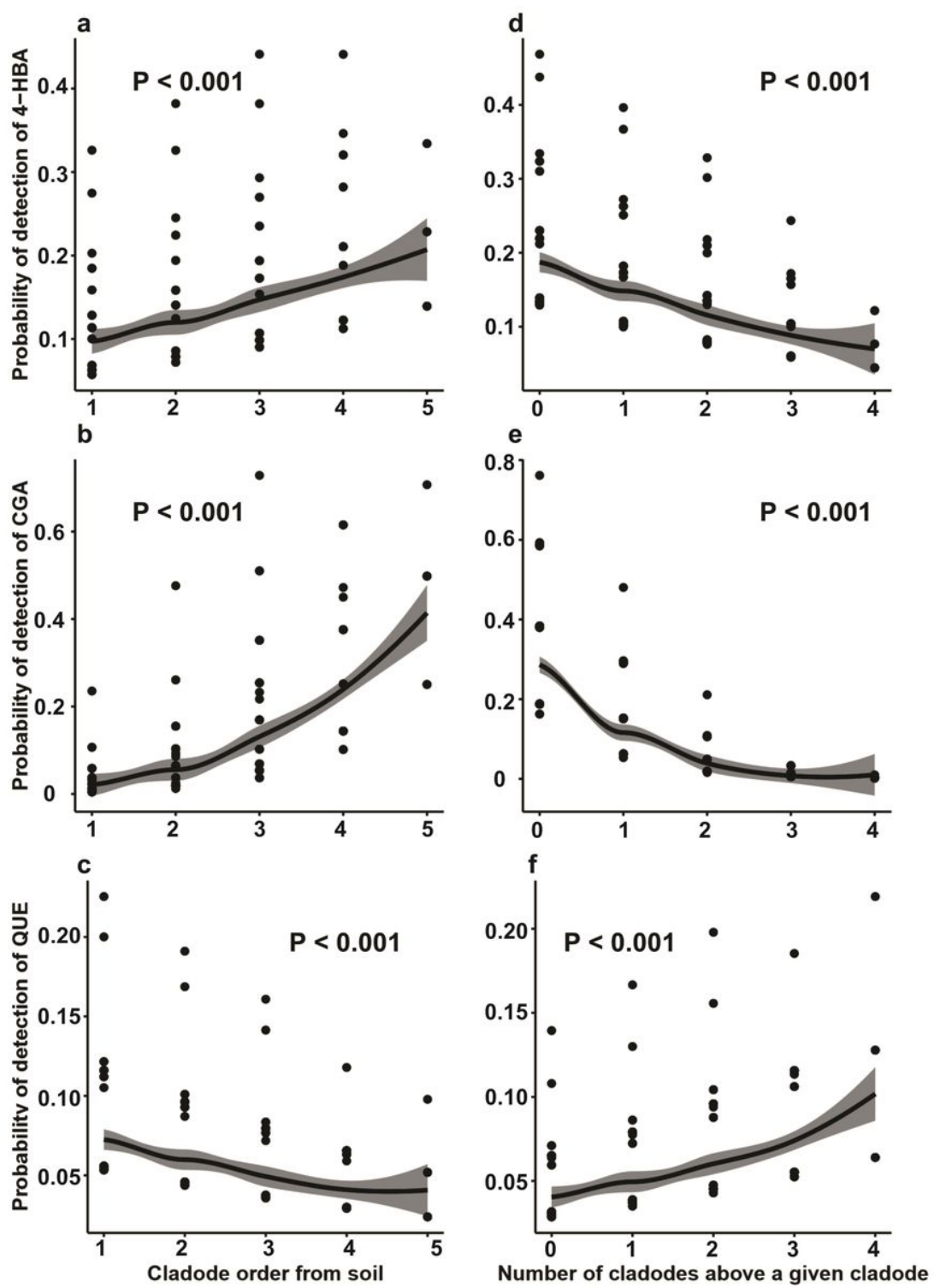

Figure 4

The effect of the cladode order above soil and the number of cladodes above a given cladode on the proportion of cladodes containing a) and d) 4-hydroxybenzoic acid (4-HBA), b) and e) chlorogenic acid (CGA), and c) and f) quercetin (QUE) in the vegetative tissues of hermaphrodite cladodes. The probability of detection of 4-HBA and CGA was higher in younger that is, higher-order cladodes or those bearing a lower number of daughter cladodes $(a, b, d$ and e) and the probability of detection of QUE was lower in younger cladodes. P - probability of adjustment in GLMM model 

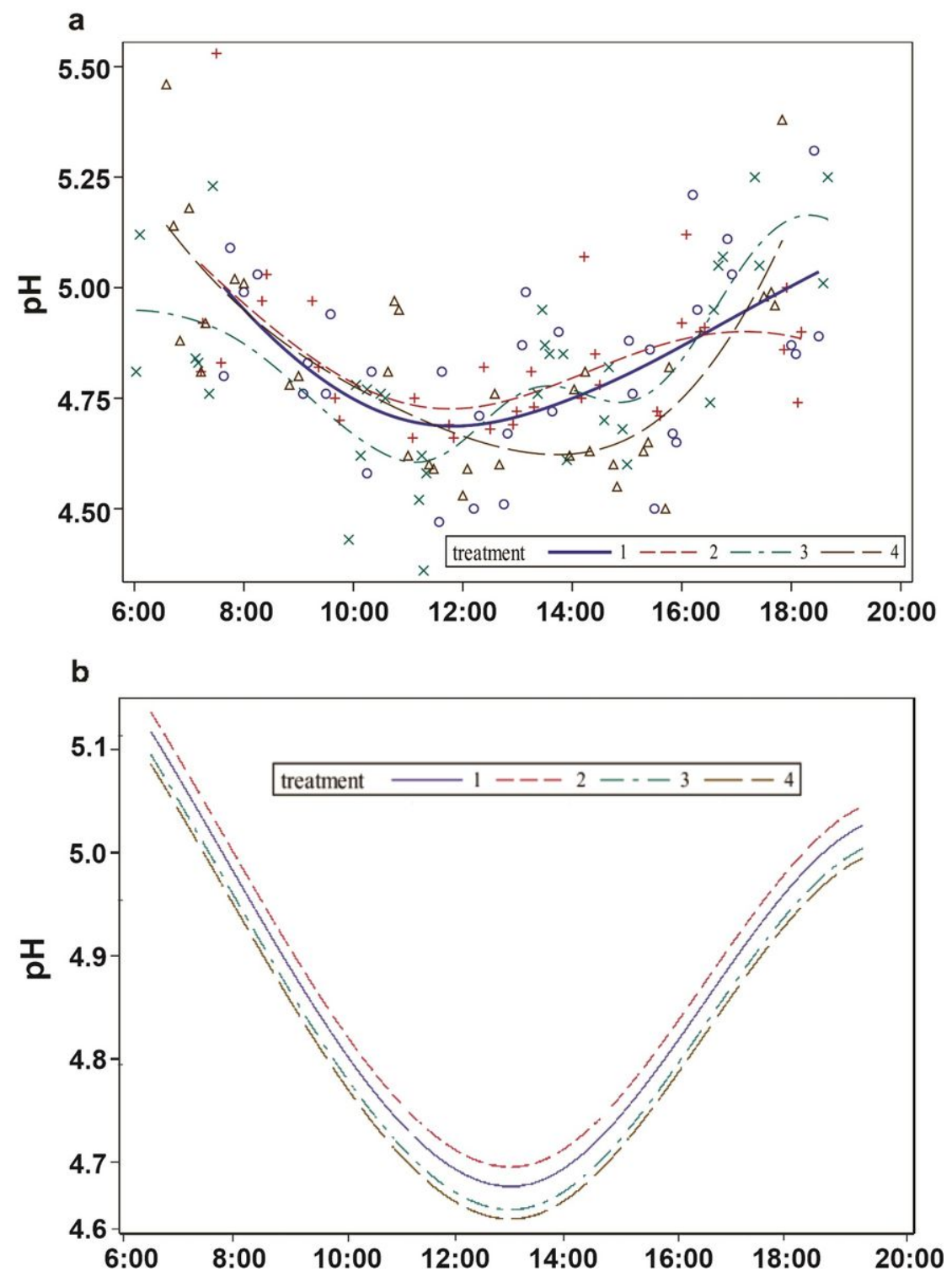

Figure 5

The dynamics of $\mathrm{pH}$ in the vegetative tissues of the hermaphrodite cladodes of 0 . robusta from branches with different treatments: 1 Uncovered apical cladode, covered basal cladode, 2 - Covered apical cladodes, uncovered basal cladode, 3 - Uncovered apical and basal cladodes, and 4 - Covered apical and basal cladodes. a) Raw data with polynomial least square regression adjustment, and b) Curves adjusted using restricted maximum likelihood in Generalized Linear Mixed Model. There was non-significant interaction between treatment and time of sampling (the spline function was the same for all treatments) 

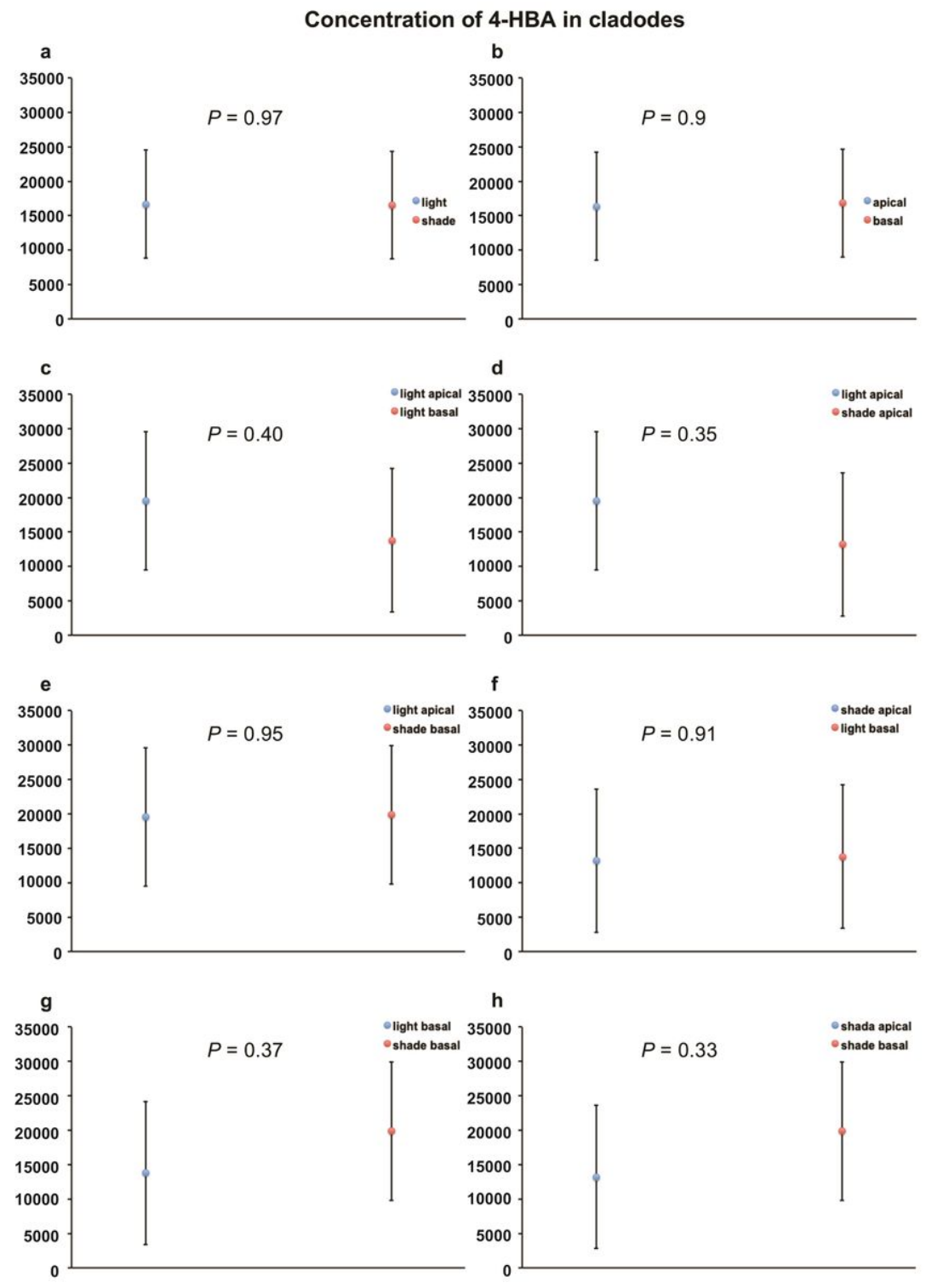

Figure 6

The effect of the treatment (shaded vs. lighted cladodes) and of the cladode position (apical vs. basal cladodes) on the concentration [absorbance] of the 4-hydroxybenzoic acid (4-HBA) in vegetative tissues of hermaphrodite individuals of 0 . robusta 
Concentration of CGA in cladodes

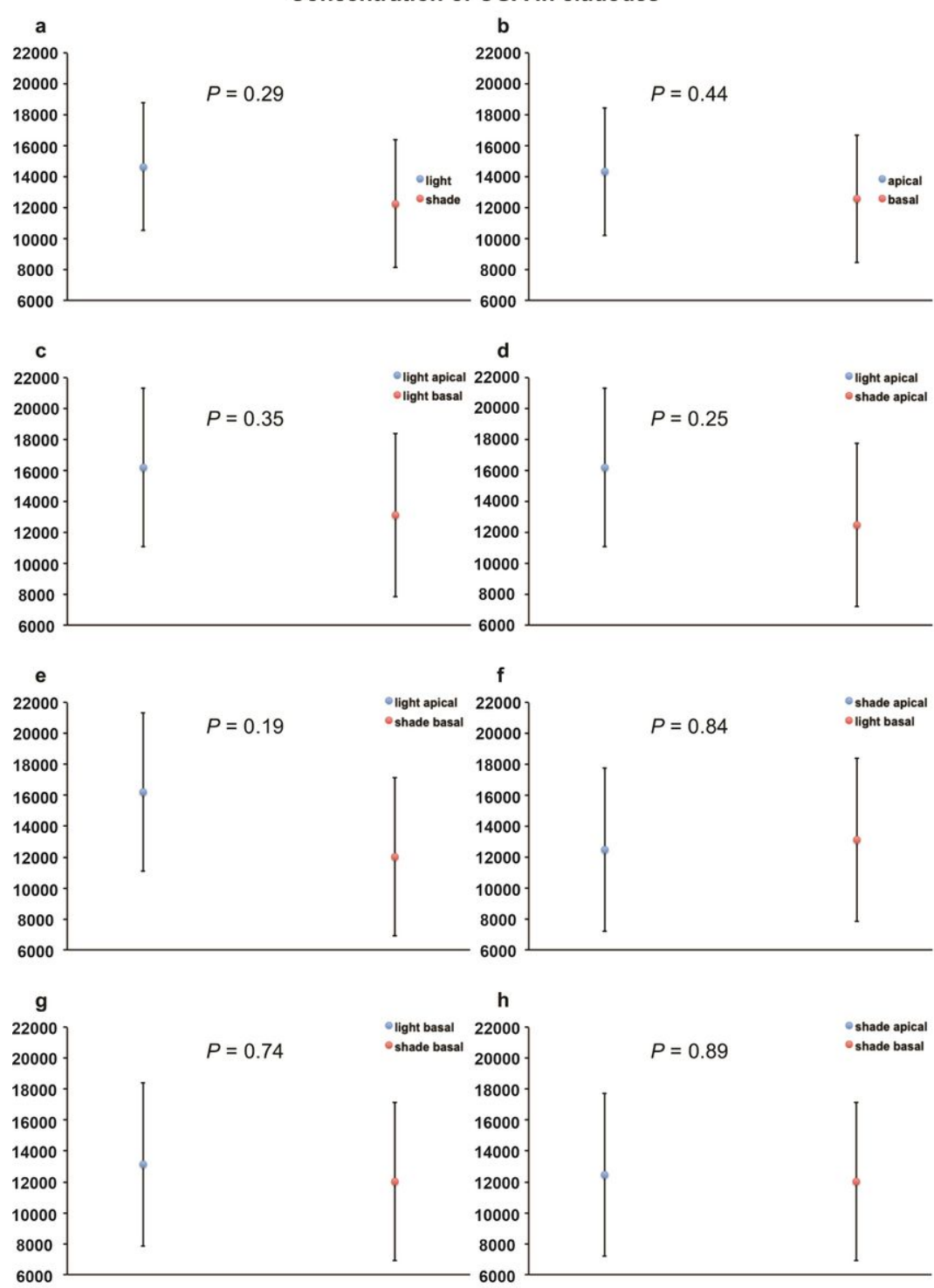

Figure 7

The effect of the treatment (shaded vs. lighted cladodes) and of the cladode position (apical vs. basal cladodes) on the concentration [absorbance] of the chlorogenic acid (CGA) in vegetative tissues of hermaphrodite individuals of O. robusta 


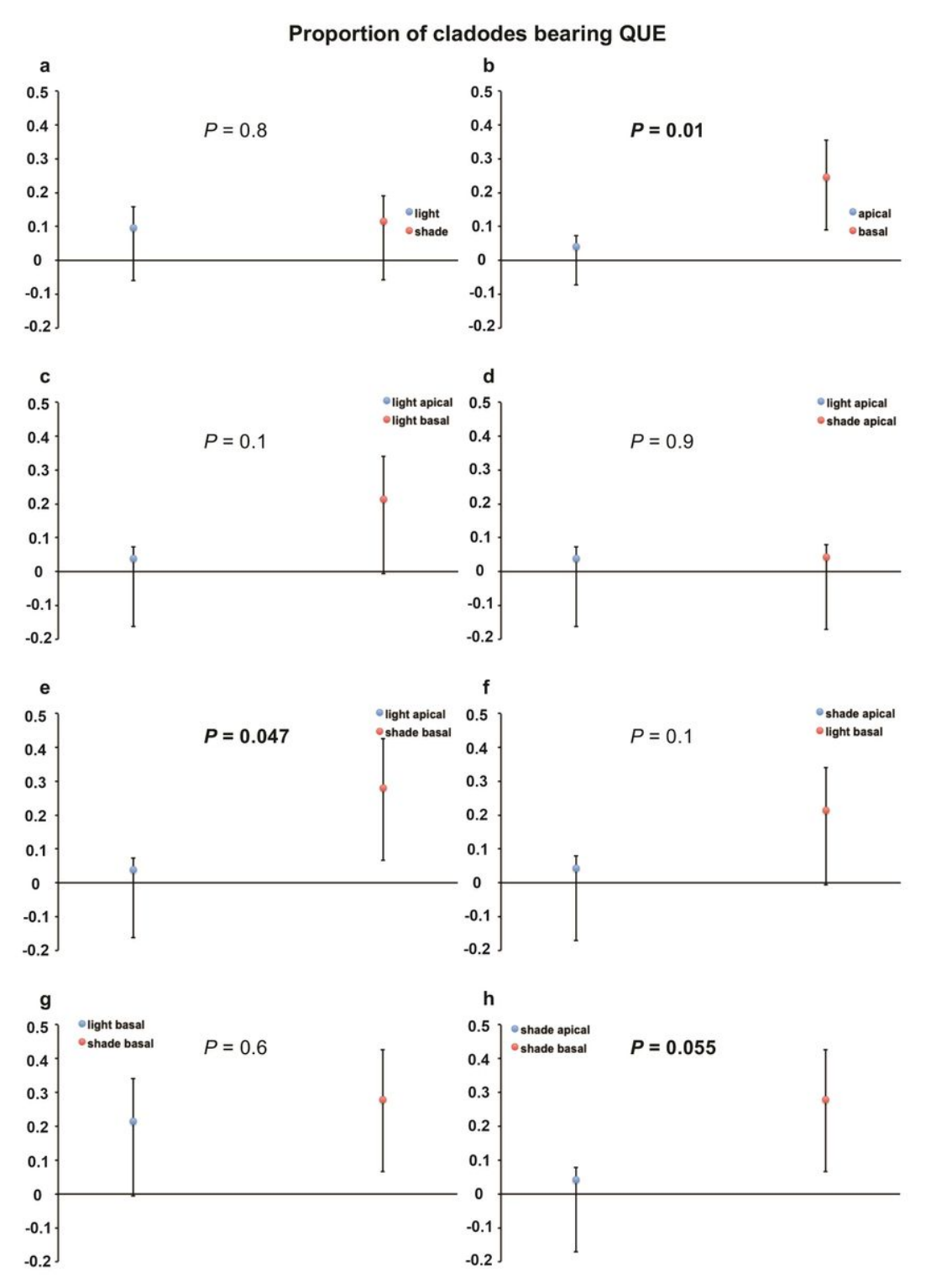

Figure 8

The effect of the treatment (shaded vs. lighted cladodes) and of the cladode position (apical vs. basal cladodes) on the probability of detection of the quercetin (QUE) in vegetative tissues of hermaphrodite individuals of 0 . robusta. We used the probability of detection of this secondary metabolite instead of its concentration because of its low incidence in the cladodes 
Proportion of cladodes bearing SAL
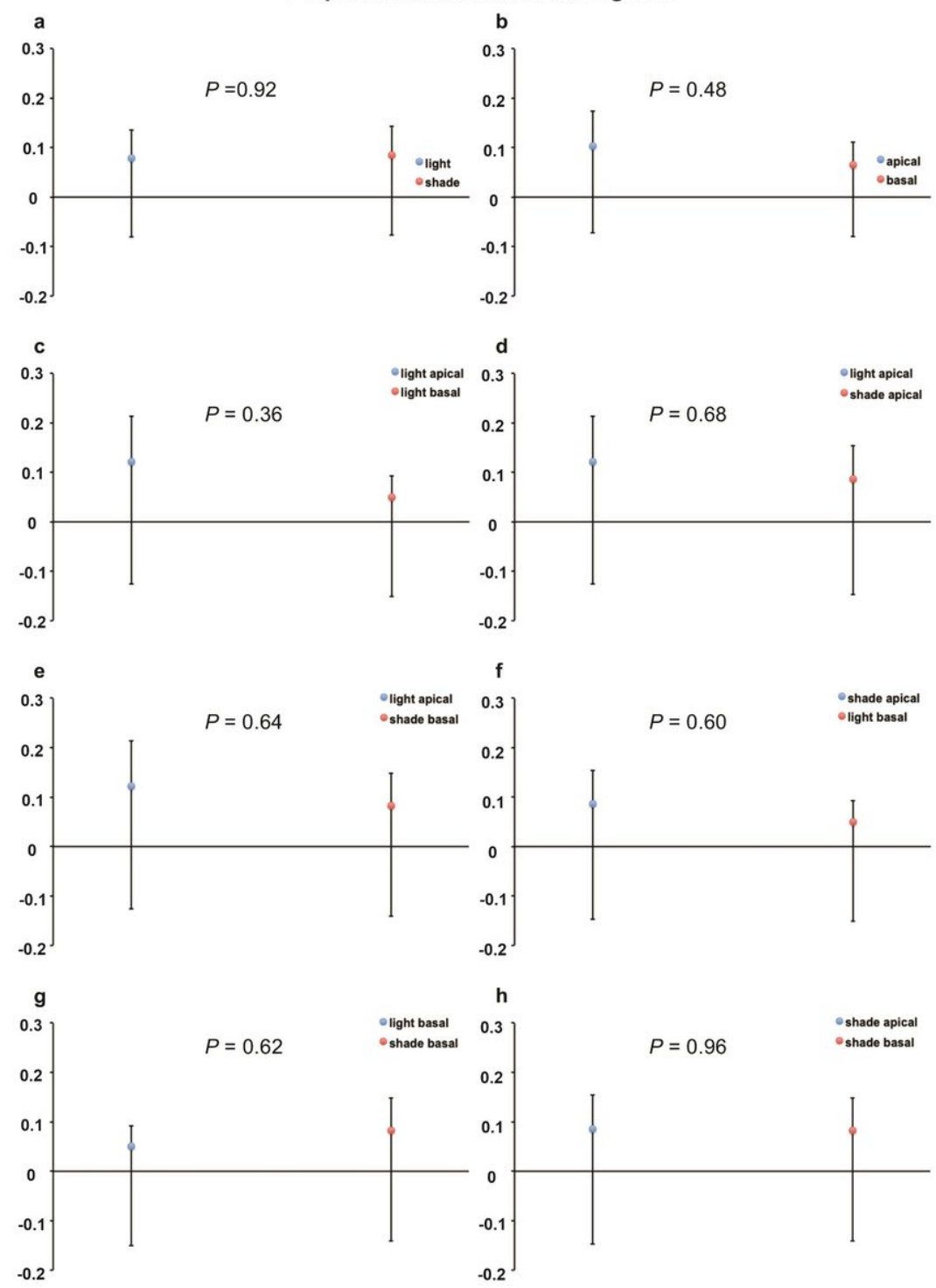

Figure 9

The effect of the treatment (shaded vs. lighted cladodes) and of the cladode position (apical vs. basal cladodes) on the probability of detection of the salicylic acid (SA) in vegetative tissues of hermaphrodite individuals of 0 . robusta. We used the probability of detection of this secondary metabolite instead of its concentration because of its low incidence in the cladodes 

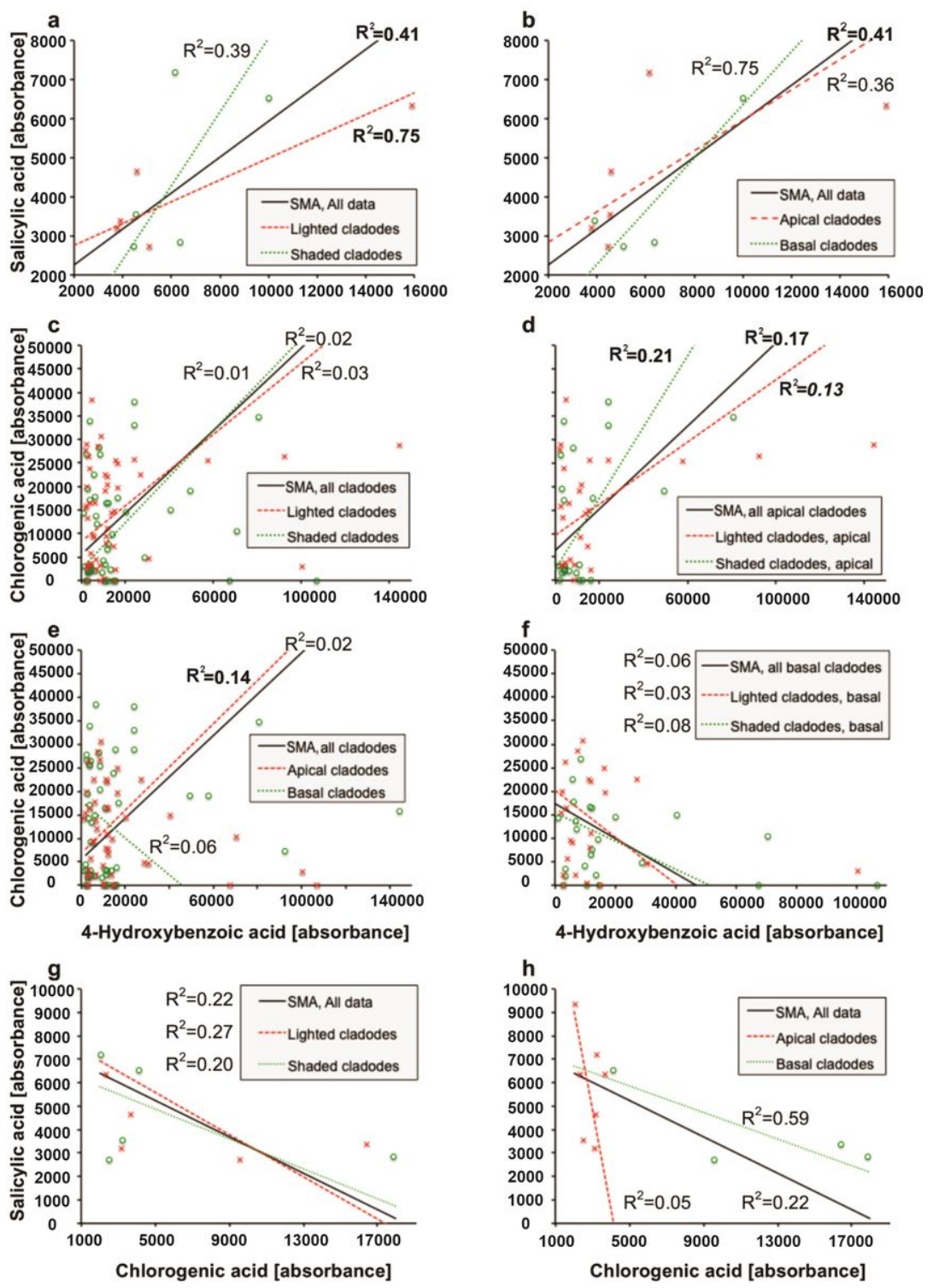

\section{Figure 10}

Relationship between the concentrations of salicylic (SA) and 4-hydroxybenzoic acid (4-HBA): a) lighted and shaded cladodes, b) apical and basal cladodes; between the concentration of the chlorogenic acid (CGA) and 4-HBA for c) lighted and shaded, d) lighted and shaded apical cladodes, e) apical and basal cladodes, f) lighted and shaded basal cladodes; between the concentration of the SA and of CGA for g) lighted and shaded cladodes, and h) apical and basal cladodes. As only very few cladodes contained SA, we performed this analysis for cladodes that contained at least on of the metabolite from each pair. R2 marked with bold for significant relationships at $\mathrm{P} \leq 0.05$ or for relationships on the edge of significance with bold italic, are placed either close to the equation lines or close to the legend. Concentrations of all secondary metabolites were expressed as absorbance 

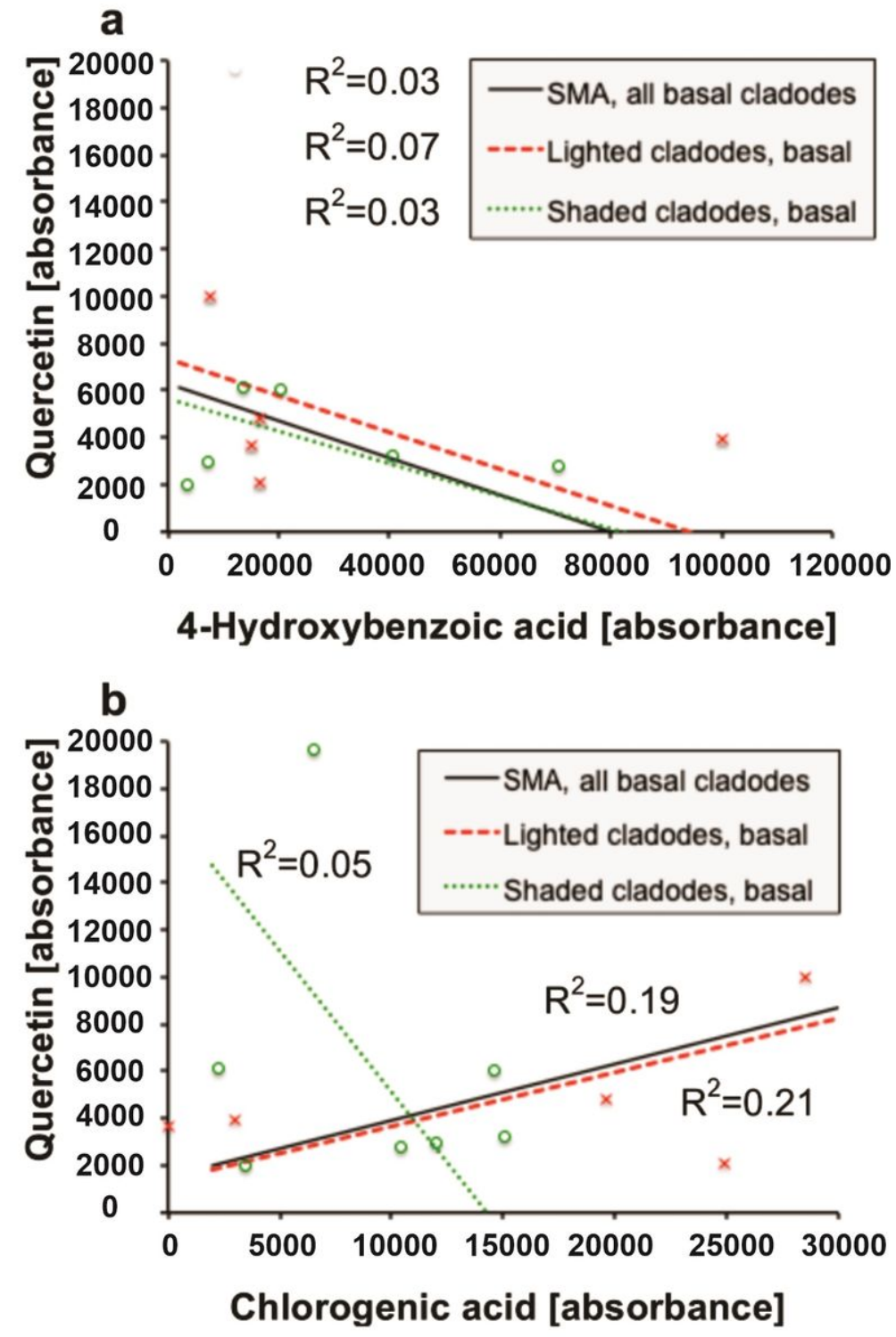

Figure 11

Relationship between the concentration of quercetin (QUE) and 4-hydroxybenzoic acid (4-HBA) for a) lighted and shaded basal cladodes and between the concentration of QUE and Chlorogenic acid (CGA) for b) lighted and shaded basal cladodes. The concentrations of the secondary metabolites for the apical cladodes were excluded from the analysis, since they were present in only two apical cladodes. As only very few cladodes contained QUE, we performed this analysis for cladodes that contained at least one metabolite from each pair. No relationship was significant. Concentrations of all secondary metabolites were expressed as absorbance 